\title{
Die tschuwaschische und mischärtatarische Brautklage
}

There is an area of nuptial laments stretching from the Baltic Sea to the Ural Mountains, where the brides of two Turkic nations also perform laments. The author thinks that the Chuvash nuptial lament has been influenced by the Mordvin one, and the Mišar Tatar lament by both the Russian and the Mordvin ones.

In vielen Kulturen muß oder mußte die Braut in irgendeiner Phase ihrer Hochzeit klagen, aber rituelle Klagelieder als wesentliches Element der Hochzeitszeremonie, so wesentlich, daß man die Hochzeit als "Hochzeit mit Klagen, Klagehochzeit" bezeichnen könnte (Nenola-Kallio 1981b, S. 59), kennt man nur in Nordosteuropa, in dem Gebiet, das vom Baltikum bis zum Ural reicht. Eine solche "Klagehochzeit" begehen oder begingen von den Slawen die Nordgroßrussen sowie die Weißrussen im Norden ihres Siedlungsgebietes, wie kürzlich T. B. Varfolomeeva (1986, S. 74-; vgl. Cistov 1982, S. 105-) berichtet, kennen sie ferner von den Balten zumindest die Litauer und von den finnischugrischen Völkern dieses Gebietes die östlichen Ostseefinnen, d. h. die Karelier, Ingrier, Wepsen, Woten und die estnischen Setukesen, weiterhin die Mordwinen und die Syrjänen.

In einigen anderen Traditionen mußte die Braut ebenfalls in mehr als einer Phase ihrer Hochzeit Klagelieder singen. So hat die westtscheremissische Braut den Klageliedern ähnliche Lieder in mehreren Phasen ihrer Hochzeitszeremonie gesungen: wenn sie ihre Geschenke verfertigt und eben bevor sie ihr Heim verlassen hat (Juadarov 1991, S. 17. 
Juadarov hat auch Klagelieder publiziert, ebd. S. 27 f. Auch Wichmann hat westtscheremissische Brautklagen aufgezeichnet: 1931, S. 207-, besonders S. 208-212, 219, 221). In anderen tscheremissischen Gebieten gab es wohl nur in der Abschiedsphase Klagen.

Auch bei zwei Türkvölkern der nordosteuropäischen Klagehochzeitregion findet man eine Hochzeit, wo in mehreren Phasen Klagelieder angestimmt werden: bei den Tschuwaschen und bei den Mischärtataren.

Unlängst hat T. Perevozčikova (1982, S. 47-; 1986, S. 22-) gezeigt, daß auch die Wotjaken Hochzeitsklagen haben. Die wotjakische Klage konzentriert sich jedoch nur auf die Phasen der Zeremonie, in der die Braut ihr altes Heim verläßt oder ihre Verwandten im neuen Heim von ihr Abschied nehmen. Die tscheremissische Hochzeit östlich der westtscheremissischen Gebiete ist wohl auch keine Hochzeit mit vielen Klagen gewesen, obwohl es möglich ist, daß auch bei dieser tscheremissischen Hochzeit früher wenigstens in jener Phase Klagelieder angestimmt wurden, wenn die Braut ihr Elternhaus verließ: "Ihre Eltern und nächsten Anverwandten weinen dabey kläglich" (G. F. Müller 1759, S. 373).

In einem südlicheren Gebiet findet man wieder Hochzeitstraditionen, in denen die Klagelieder wohl in mehreren Phasen der Zeremonie gesungen worden sind oder gesungen werden. Auch bei den ungarischen Hochzeiten sind Klagen angestimmt worden. Sie gehören vor allem zu der Phase, in der die Braut das elterliche Heim verläßt. Zwar sind in den meisten Gebieten auch in diesem Abschnitt des Geschehens anstelle der Klagen Hochzeitslieder, Abschiedslieder gesungen worden; daß diese Lieder stellenweise als Klagelieder (sirató) bezeichnet worden sind, gibt jedoch Grund für die Annahme, daß "die dann gesungenen Lieder früher an Totenklagen erinnern konnten" (MNT III/A, S. XXIX). Offenbar sind zumindest stellenweise bei der ungarischen Hochzeit auch am Vorabend der Hochzeit Klagelieder angestimmt worden, denn von diesem Abend, an dem sich die Braut von ihren Freundinnen und Freunden verabschiedet, ist die Bezeichnung siratóest 'Klageabend' verwendet worden (a.a. O. S. XXIV). Ungarische Hochzeitsklagen sind nur unter den Csángós in Rumänien aufgezeichnet worden, doch weiß man aus sekundären Quellen, daß auch die Szekler in Transsilvanien und die Ungarn im Gebiet von Gömör (zwischen der 
mittleren Slowakei und Ungarn) solche gehabt haben (Voigt 1987, S. 1-, 6-). Auch aus Bulgarien, und zwar aus dem Gebiet der Rhodopen im Südwesten des Landes, sind nach dem Zweiten Weltkrieg Hochzeitsklagen aufgezeichnet worden, die die Braut an den drei der Hochzeit vorangehenden Tagen vorgetragen und in denen sie sich von ihren Angehörigen verabschiedet hat (Čistov 1982, S. 105-; Voigt 1987, S. 4, 6-).

Wie aus obigem hervorgeht, ist das Gebiet der Brautklage nicht einheitlich. Voigt nimmt an, daß sowohl die Klagen der Ungarn als auch die im bulgarischen Rhodopen-Gebiet unabhängig von den russischen und nördlichen finnisch-ugrischen Brautklagen entstanden seien (1987, S. 7). Den bulgarischen Klageliedern hat auch Čistov seine Aufmerksamkeit zugewandt und ebenfalls die Meinung vertreten, daß diese kurzen Klagelieder nicht dieselben Merkmale wie die Brautklagen im russisch-finnisch-ugrischen Gebiet des Nordens aufweisen (Čistov 1982, S. 106-). Das Gebiet jedoch, in dem die Brautklage als wesentlicher Bestandteil zur Hochzeitszeremonie beiträgt, das nördliche Gebiet der Klagehochzeiten, ist einheitlich. Wie schon erwähnt, erstreckt es sich vom Baltikum bis zum Ural.

Es stellt sich die Frage, ob der Ursprung der Hochzeit mit Klagen in einer der Traditionen dieses Gebiets zu suchen ist. Man kann davon ausgehen, daß die Kultur, in der sich die Brautklage entwickelt hat, eine agrarische Kultur war. Diese Meinung haben u. a. A. Nenola-Kallio (1981a, S. 60) und M. Sarmela (1981, S. 27) vertreten. Man sollte deshalb den Ursprung der Brautklage nicht ganz im Norden suchen, wo z. B. die Syrjänen noch im 18. Jh. hauptsächlich als Jäger und Fischer lebten (Žerebcov 1985, S. 26).

Einige Forscher sind geneigt gewesen, die nordrussische Brautklage oder die nordrussische Hochzeit mit Klagen als primär anzusehen. M. Haavio beispielsweise war der Meinung, daß die syrjänische Brautklage von den Russen übernommen worden sei (1930, S. 133). A. NenolaKallio, die die Klagelieder der Ostseefinnen, besonders die der Ingrier, untersucht hat, nimmt an, daß sich die Ostseefinnen die Sitte, im Zusammenhang mit der Hochzeit zu klagen, von den Russen angeeignet hätten, die ostseefinnische Brautklage an sich jedoch eigene, auf der Grundlage der alten Totenklage entstandene Dichtung darstelle (1982, S. 116 f.). Der Kenner der nordrussischen Tradition Čistov wiederum 
ist der Ansicht, daß die nordrussische Brautklage ziemlich jung und frühestens während des 14., 15. Jahrhunderts entstanden sei (1982, S. 108). Ich habe früher die Auffassung geäußert, daß die finnischugrische, insbesondere die mordwinische, Brautklage deutlich älter als die nordrussische sei (Bartens 1990, S. 115-). Ebenfalls habe ich angenommen, daß eine mordwinisch-ostseefinnische, vielleicht sogar eine mordwinisch-ostseefinnisch-baltische, Verbindung bei der Entstehung der Klagehochzeit gegeben ist (Bartens 1991, S. 46-). Schließlich habe ich angenommen, daß die syrjänische Brautklage ihren Anteil an der Hochzeitszeremonie unter Einfluß der ostseefinnischen Brautklage erweitert hat (Bartens 1991, S. 45-). Die kulturellen Unterschiede zwischen den tscheremissischen Gebieten können sich durch die unterschiedliche Einflußnahme der Nachbarvölker erklären; das westtscheremissische Gebiet war dem russischen Einfluß ausgesetzt.

Wie bereits erwähnt, haben auch die Bräute zweier Türkvölker, der Tschuwaschen und der Mischärtataren, innerhalb des vom Baltikum bis zum Ural reichenden Klagehochzeitsgebietes in mehreren Phasen der Hochzeitszeremonie geklagt. Bei einigen anderen Türkvölkern war es üblich, an einer Stelle der Zeremonie zu klagen. Und zwar geschah dies, wenn die Braut während einer kasimovtatarischen, christlich-tatarischen (aus dem Gebiet Podberežinskij), nogaischen, baschkirischen oder kirgisischen Hochzeit Abschied von ihren Anverwandten nahm (Muchamedova 1972, S. 167-). (Es ist auffällig, daß alle diese Völker außer den Kirgisen europäisch sind.) Bei dieser Gelegenheit klagten die Braut und ihre weiblichen Verwandten und Freundinnen; man bezeichnete das Geschehen mit einem kausativen Ausdruck (im Kasimovtatarischen, im Nogaischen: Muchamedova ebd., im Kirgisischen: Džumagulov 1960, S. 39), und auch die Mischärtataren verwendeten in manchen Gebieten ein kausatives Verb zur Bezeichnung des Klagens (Muchamedova ebd.). Auch bei mindestens einem Mongolenvolk, den Kalmücken, ist eine Klage überliefert, die das Klagen der Braut bezweckt (Chabunova 1986, S. 329). (Auch in diesem Fall handelt es sich also um ein europäisches Volk.) Hin und wieder stößt man auch im finnisch-ugrischen Gebiet auf ähnliche kausative Termini.

Sowohl in der syrjänischen als auch der wotjakischen Tradition sind diese kausativen Benennungen der Brautklagen bekannt. Das ungari- 
sche Kausativderivat zeugt ebenfalls von dieser archaischen Haltung. Aber die kausative Brautklage beschränkt sich nicht auf den türkischpermisch-ungarischen Raum. Konkka bemerkt in ihrer Arbeit zur karelischen Brautklage, daß "die über die Brautklage befragten Informanten meist den Ausdruck man beweint die Braut verwenden" (Konkka 1985, S. 103). Die mordwinische Braut gebraucht selbst den Ausdruck "Beklagt mich wie eine Tote!" (Bartens 1990, S. 120).

Man kann annehmen, daß der Gebrauch eines kausativen Derivates mit der ursprünglichen Funktion der Klage in Beziehung zu setzen ist: Die aus dem Heim scheidende Braut wurde wie eine Tote beweint (Bartens 1991, S. 44-). Džumagulov interpretiert die Brautklage der Kirgisen ebenso: Indem die Verwandtschaft ein Mitglied der eigenen Familie zu einer anderen Sippe geleitete, verabschiedete sie sich für immer von ihm, als handele es sich um einen Toten (Džumagulov 1960, S. 39).

Die Erforscher der Klagelieder haben dann auch eine Entwicklungslinie angenommen, die von der Totenklage zur Brautklage führt (Čistov 1982, S. 105; Nenola-Kallio 1982, S. 116-; Károly 1988, S. 615). Diese Auffassung ist allein schon wegen der Verbreitung der Klagearten, die bei der Totenklage größer ist als bei der Brautklage, die natürliche.

Die Totenklage ist beinahe universell, wie z. B. Haavio konstatiert hat (1933-35, S. 3-). In der Kultur der slawischen Völker hat die Totenklage eine große Bedeutung gehabt (z. B. Mahler 1935). Für die Türkvölker ist die Totenklage "soziologisch äußerst wichtig" gewesen und ist es weiterhin (von Gabain 1963, S. 215). Von Gabain hat sogar angenommen, daß die den Türkvölkern so typische Gattung der epischen Dichtung, der Heldengesang, aus der alttürkischen Totenklage entstanden sei (ebd.). Auch Harva hat auf die Totenklage der Türkvölker hingewiesen (Harva 1933, S. 196). Unter den finnisch-ugrischen Völkern ist sie ebenfalls wohl überall verbreitet oder verbreitet gewesen. Aus einigen Gebieten liegen nur spärliche Informationen vor. Von ostjakischen Klageliedern gibt es meines Wissens nur mittelbare Kenntnis (Bartens 1986b, S. 12). Von den Lappen weiß man, daß ihre östlichen Gruppen, die Skolt- und Kolalappen, Totenklagen kennen; publiziertes Material darüber existiert nicht. Die Rekrutenklage ist deutlich eine spezifische Totenklage. Die Mordwinen verwenden z. B. dieselbe Bezeichnung für beide Ǩlagearten. Die Rekrutenkilage wurde besonders 
im alten Rußland tradiert, das den 25jährigen Kriegsdienst kannte. Die Familie verabschiedete sich von dem in den Dienst ziehenden Rekruten wie von einem Toten; wenn ein mordwinischer Rekrut nach seiner Dienstzeit noch in sein Heimatdorf zurückkehrte, hatte er keinen Namen, also keine Identität, mehr. Er war bis zu seinem Tode saldat (Paasonen 1891, S. XVIII). Auch die mordwinische Braut verlor ihre alte Identität, ihren alten Namen (vgl. Bartens 1990, S. 110.)

Die Totenklagen werden im allgemeinen an den Verstorbenen gerichtet; in ihnen wird der Verstorbene angesprochen. (In vielen finnisch-ugrischen Sprachen wird nicht von dem "Verstorbenen" gesprochen, sondern vom "Sterbenden", d.h. zur Bezeichnung dient die Form des Partizips der unvollendeten Handlung. Es läßt sich keine Klarheit darüber gewinnen, ob der Verstorbene insbesondere in den sechs Wochen nach seinem Tod der "Sterbende" war, in denen er nach allgemeiner Auffassung Verbindung zu seiner alten Umgebung hatte, bevor er aus der mittleren Welt in die untere Welt einging, und in welcher Zeit dem "Sterbenden" besonders häufig Klagelieder vorgetragen wurden.)

Es gibt auch einige Belege dafür, daß der Text umgekehrt gestaltet worden ist, d.h. der Verstorbene die Hinterbliebenen anspricht. Mittelalterliche Chroniken berichten, daß die Ungarn ihren verstorbenen Helden Klagelieder gesungen haben, bei denen der Text aus dem Blickwinkel des Verstorbenen gestaltet war und die sich in der Form der 1. Person bewegten (MNL 4, S. 448). In den Gedenkfeiern für die Toten werden bei den Tscheremissen Lieder vorgetragen, für die Bereczki den Terminus lament verwendet. Er charakterisiert die Lieder folgendermaßen: "These songs are of a responsive character; sometimes the dead is addressed by the mourners, sometimes those left behind are addressed by the corpse" (Bereczki 1971, S. 66); der Tote hat einen Vertreter bei der Gedächtnisfeier.

Die meisten Brautklagen der Klagehochzeit werden wiederum von der Braut selbst vorgetragen. In einigen Gebieten kann zwar statt der Braut eine Klagefrau oder sogar ein Klagechor die Klagen vortragen. Unabhängig davon, ob die Braut selbst oder diese vertretend eine Klagefrau oder ein Chor die Klage anstimmen, wird sie in der 1. Person Singular vorgebracht. (Eine kleine Ausnahme stellen einige von Wich- 
manns westtscheremissischen Klageliedern der Braut dar, in denen die Vortragende den Text in der 2. Person Singular gestaltet - Wichmann 1931, S. 221-.)

Das Subjekt der Klage ist also die Braut, d.h. aus dem Objekt der ursprünglicheren Klageform, der Totenklage, ist die handelnde Person geworden. Wie dies geschehen ist, darauf habe ich besonders im Hinblick auf die mordwinische Tradition eine Antwort zu finden versucht; ich bin dabei zu der Annahme gelangt, daß die mordwinische Braut mit den ersten Klageliedern versucht hat, Kontakt zu ihren Vorfahren aufzunehmen und dabei ihr sich veränderndes Verhältnis zu diesem Teil ihrer Familie zu regeln (Bartens 1990, S. 120). Die Braut mußte also selbst aktiv handeln. Auch in anderer Hinsicht mußte sie aktiv werden: In vielen Kulturen mußte die Braut beim Verlassen ihrer Familie und ihres Heimes Trauer zeigen. So wurde aus der Braut ein nicht mehr mit einer Toten vergleichbares Objekt der Klagelieder, sondern gerade das aktive Subjekt der Klage.

Man hat jedoch auch in einer Tradition, zu der keine eigentliche Klagehochzeit gehört, einer "zu beweinenden" Braut einen bestimmten Grad an Aktivität abverlangen können. Während der letzten Nacht singen die älteren Freundinnen und die Frauen der Verwandtschaft der Kalmückenbraut Lieder, die sie zum Weinen bringen sollen. In diesen Gesängen enden die Phrasen oft in Schluchzen (Sivljanova 1986, S. 353). Von der Braut wird erwartet, daß sie lauthals weint (Chabunova 1986, S. 329). (Auch die Braut einer Klagehochzeit weint oft lauthals, wenn die Frauen, die sie zum Weinen bringen sollen, ein Klagelied für sie singen: Siehe das Klagelied einer karelischen Braut bei Konkka 1985, S. 109; Klagelied einer syrjänischen Braut bei Mikušev Čistalev 1968, S. 13). Die Kalmückenbraut wird auch in der Hinsicht vom Objekt zum Subjekt des Geschehens, daß die Klagefrauen ihre Klagen in ihrem Namen darbringen, und zwar in der 1. Person Singular: "Als ich bei meiner Mutter war / war ich wie ein sorgloses Kalb. / Als ich von dir, Mutter, getrennt wurde, / wurde ich wie zu einem alten Seilstück" (Chabunova 1986, S. 329). (Die Klagesituation der Kalmückenhochzeit besitzt auch einen anderen Wesenszug, der darauf hinweisen könnte, daß es sich nicht nur um die Beziehung zwischen der Verwandtschaft, die zurückbleibt, und der Braut, die wie eine Tote vom 
Heim scheidet, handelt. Die Klagesituation steht nämlich in Verbindung mit der Morgenröte: Die Braut muß während der Nacht bis zum Morgengrauen klagen. Die Welt der Toten steht in Opposition zur Welt der Lebenden: Alles geschieht dort spiegelbildlich zur realen Welt, so daß die Nacht der Toten bei unserem Morgengrauen beginnt. Der Zeitpunkt des Vortragens der Brautklage könnte dadurch erklärt werden, daß durch die Klage der Kontakt zwischen der Braut und ihren Vorfahren aufrechterhalten wird. Diese Beziehung der Braut zu ihren Vorfahren ist jedenfalls der Ausgangspunkt der Brautklagen, die die mordwinische Braut vor dem Morgengrauen anstimmt.)

Auch bei den Türkvölkern, zu deren Hochzeit die Brautklage nur als Abschiedsklage gehört, hat die Handlung der Braut Züge inne, die so interpretiert werden können, daß das Objekt des Beklagens quasi zum Subjekt der Handlung wird.

Die tschuwaschischen und mischärtatarischen Bräute haben ihren Status eines Objekts völlig in den eines Subjekts verändert. Von zu beklagenden Objekten sind sie zu Subjekten geworden, die die Hochzeitszeremonie in mehreren Phasen mit ihren eigenen Klageliedern tragen.

Bei der tschuwaschischen Hochzeitszeremonie kann man drei verschiedene Phasen unterscheiden: 1. die Brautwerbung und das Entrichten des Brautgeldes sowie möglicherweise eine kirchliche Trauung, 2. die Hochzeit bei der Braut zu Hause, 3. das Überführen der Braut in das Heim des Bräutigams, die Empfangszeremonie dort sowie die Hochzeitsfeier und das Geleiten der Braut in das Ehebett.

Die Zeremonie beginnt mit der Werbung, die von einem ausgewählten Brautwerber ausgeführt wird. Sobald man auch den Preis der Braut ermittelt hat, brechen die Eltern des Bräutigams am festgelegten Tag auf, um das Brautgeld zu bezahlen. Der Bräutigam nimmt an diesem Geschehen nicht teil (Prokop'ev 1903, S. 4, 5-). Die Braut und der Bräutigam lassen sich kirchlich trauen, manchmal schon drei, vier Tage vor der eigentlichen Hochzeit. Ohne miteinander zu sprechen, kehren sie beide in ihr eigenes Heim zurück und sehen sich nicht mehr vor der Hochzeit (Prokop'ev 1903, S. 10). 
Die Hochzeit beginnt am gleichen Tag im Haus der Braut und des Bräutigams; das gemeinsame Feiern im Haus der Braut beginnt erst am Abend des zweiten Tages.

Die Teilnehmer des Festzuges des Bräutigams werden unter den Verwandten des Bräutigams ausgewählt, die in sein Haus eingeladen worden sind. Der Bräutigam wird in einen Speicher geführt und dort in sein Hochzeitsgewand gekleidet. Die Ältesten der Familie haben das Vorhaben gesegnet, und der Bräutigam empfängt den Segen seiner Eltern. Während allen Abschnitten der Hochzeit wird im Zusammenhang mit Gebeten und Segen rituell Bier gereicht und getrunken. Das Festmahl, die Musik und der Tanz beginnen. Danach beginnt die Gesellschaft einen Besuchsrundgang in den Häusern der Verwandten des Bräutigams; die Eltern des Bräutigams bleiben daheim. Man übernachtet in einem der Häuser der Verwandtschaft. Am nächsten Abend bricht man zum Haus der Braut auf.

Auch im Haus der Braut beginnt die Zeremonie mit dem Ankleiden, nachdem die Verwandten eingetroffen sind. Die Braut wird von den Frauen ihrer Verwandtschaft und ihren Freundinnen ebenfalls in einem Speicher angezogen. Dort wird sie zum Schluß mit einem großen Tuch umhüllt, der nur einen kleinen Schlitz um die Augen freiläßt. Danach beginnt die Braut bereits im Speicher mit den Brautklagen.

Dann wird sie zurück in den Wohnraum geführt. Die Tochter erhält den Segen der Eltern. Dieser entspricht fast wortwörtlich dem, den der Bräutigam in seinem Haus von seinen Eltern empfangen hat. Die Tochter sagt weinend: "Ich bin euch überflüssig geworden!" und die Eltern erwidern: "Wir haben diesen Brauch nicht festgelegt, sondern er wird von den Vorfahren seit uralten Zeiten überliefert!" (Auch im Haus des Bräutigams hat man sich auf die Vorfahren berufen.)

Darauf setzt sich die Tochter mit ihren Freundinnen auf eine Pritsche vor dem Ofen und beginnt mit dem Vortragen der Klagelieder. Nur für kleine Pausen innehaltend, weint sie während der ganzen Hochzeit, so daß sie, wenn sich die Hochzeit ihrem Ende nähert, ihre Stimme fast verloren hat, berichtet Prokop'ev (a.a.O. S. 22). Die Braut erwähnt in ihren Klagen der Reihe nach ihre Eltern, die sonstigen Familienangehörigen, die Verwandten, die Freundinnen und die Dorfbewohner. Dem, den sie jeweils in ihrer Klage erwähnt, wird ein Schöpflöffel Bier 
gereicht. Der Betreffende trinkt das Bier und legt ein Geldstück für die Braut in den Schöpflöffel.

Nach dem Festmahl bricht auch diese Gesellschaft auf, um die Häuser der Verwandtschaft zu besuchen. Die Braut fährt im Wagen stehend. Die ganze Zeit, die die Hochzeit andauert, berührt sie den Boden nicht - ein Mann aus dem Geleit trägt sie immer aus dem Wagen ins Haus und zurück.

Am Abend des darauffolgenden Tages läßt sich die Braut mit ihrem Gefolge in einem im voraus vereinbarten Haus von Verwandten nieder. Zur gleichen Zeit hat der Bräutigam bereits das Haus der Braut erreicht. Im Haus der Verwandten wechseln die Brautführerinnen die Kopfbedeckung der Braut. Die Kopfbedeckung des Mädchens wird gegen die Kopfbedeckung einer verheirateten Frau eingetauscht. Dieser Kopfbedeckungstausch repräsentiert den Statuswechsel der Braut: Das Mädchen wird zur verheirateten Frau. Danach wird die Braut im Wagen zum Haus ihres Vaters, ganz dicht neben die Treppe, gebracht. Von dort holt sie der Bräutigam mit seinem Geleit und bringt sie in den Wohnraum.

Der Bräutigam selbst ist, wie schon erwähnt, am gleichen Abend mit seinem Geleit eingetroffen. Der Zeremonienmeister des Geleits hat zuerst beim Vater der Braut angefragt, ob das Geleit empfangen wird oder nicht. Nachdem der Zeremonienmeister dreimal angefragt hat und er dreimal eine bejahende Antwort erhalten hat, hält er eine lange Rede in poetischem Stil. Nach der Rede steigt das Geleit des Bräutigams von den Pferden und betritt den Wohnraum, wo das Festmahl beginnt. Diesem geht jedoch ein Gebet voraus, bei dem die versammelte Gesellschaft mit dem Gesicht zur Tür hin steht; zum Schluß des Gebets geht der Herr des Hauses zur Tür und verneigt sich dort bis zur Erde.

Sobald sich die Braut eingefunden hat, holt sie der Bräutigam mit seinen Gefährten der Zeremonie gemäß in den Wohnraum - im Flur hat sie der Zeremonienmeister mit Bier erwartet, zuerst hat der Bräutigam getrunken und die Braut beim Namen genannt, dann hat die Braut getrunken und ihrerseits den Bräutigam beim Namen genannt. Im Wohnraum werden sie beim Tisch von den Eltern beider, die Biergefäße in den Händen halten, erwartet; vor diesen kniend erhalten sie ihren Segen und Rat. Danach beginnen die Vergnügungen. 
Nach dem Frühstück brechen die Eltern des Bräutigams in ihr eigenes Heim auf, wo sie den Empfang der Braut vorbereiten. Die Mitgift der Braut wird ebenfalls dorthin gebracht. Auch der Bräutigam bricht mit seinem Geleit auf; er bleibt jedoch am Rande des Dorfes und erwartet die Braut dort. Die Braut verabschiedet sich zu Hause von ihren Angehörigen, Verwandten und Freundinnen mit Klageliedern und fährt dann mit ihrem Geleit in einem Wagen, immer noch unter dem Tuch verborgen, zum Bräutigam, der sie erwartet. Die Braut wird in den Wagen des Geleits des Bräutigams umgesetzt. Das Geleit der Braut kehrt in das Heim der Braut zurück, während das Geleit des Bräutigams mitsamt der Braut zum Haus des Bräutigams fährt.

Dort wird die Braut bis vor die Treppe gefahren. Nach zeremoniellen, Fruchtbarkeitsmagie und Vorsichtsmaßnahmen enthaltenden Empfangsriten wird sie in das Haus getragen und auf eine Pritsche vor dem Ofen gesetzt. Die jungen Frauen der Verwandtschaft des Bräutigams kochen eine traditionelle Mehlklößchensuppe, die zum Ritus gehört. Dann wird das große Tuch vom Haupt der Braut entfernt. Dies geschieht folgendermaßen: Ein jüngerer Bruder oder junger Verwandter des Bräutigams hebt ihn mit einem verästelten Zweig, in dessen Astgabelungen Mehlklößchen gesteckt worden sind, vom Haupt der Braut. Danach wird die Braut zum Fluß oder zu einem Brunnen gebracht, damit sie Wasser holt. Wieder im Wohnraum angekommen, läßt sich die Braut vor dem Ofen nieder, wobei sie sich auf eines ihrer Knie stützt. Die Schwiegereltern sitzen am Tisch mit dem Bierschöpflöffel in der Hand und segnen die Schwiegertochter. Danach gratulieren und segnen auch die anderen Anwesenden die Braut. Und so ist die Zeit herbeigekommen, die Jungverheirateten in den Speicher zu bringen, wo ihr Ehebett bereitet ist. Am nächsten Tag verteilt die Jungvermählte ihre Geschenke an die Familie und die Verwandten ihres Mannes.

Mit dieser Beschreibung von Prokop'ev stimmen die übrigen Beschreibungen alter tschuwaschischer Hochzeiten überein: die von Paasonen (MSFOu 94, 1949, S. 1-68), Mészáros (1909, S. 429-464), Sirotkin (1965, S. 23-33) und die größtenteils auf Sirotkin basierende Beschreibung von Osipov (1985, S. 44 49). Ferner finden sich in den einzelnen Schilderungen einige wichtig erscheinende zusätzliche Charakteristika. 
In der Beschreibung von Paasonen macht der Anführer des Umzuges während der Besuchsrunde durch die Häuser der Verwandtschaft, die zu der "Hochzeit der Braut" gehört, einen Kreis um den Umzug, sobald sich der Umzug außerhalb des Dorftors befindet (d.h. er beschützt ihn), opfert den "bösen Geistern" Geld und bittet sie um ihren Schutz und um die Erlaubnis, die Hochzeit zu feiern. Danach steigt die Braut vom Wagen herunter - sie ist mit ihren Freundinnen stehend gefahren und jedes Mal, wenn man sich vom Wagen ins Haus und zurück begeben hat, ist sie getragen worden; ihre Füße haben den Boden nicht berührt - und geht mit einer der Frauen zur Seite, opfert Brot und betet: "Großvater, Großmutter! Segnet mich! Lasst meinen Bräutigam milde mit mir verfahren! Haltet mich nicht davon ab, zu gebären! Gebt mir Glück und Gesundheit!' Dann fährt man in das folgende Haus von Verwandten (Paasonen 1949, S. 35).

$\mathrm{Da}$ die Braut beim Verlassen ihres elterlichen Hauses Geschenke an ihre eigenen Angehörigen verteilt, wie Paasonen angibt (1949, S. 52), wird auch von Mészáros mitgeteilt (1909, S. 459).

Zum Verlassen des Heimes gehören die Abschiedsklage der Braut und die Abschiedsküsse, die sie ihren Eltern gibt (Paasonen 1949, S. 62; Mészáros 1909, S. 459). Während die Braut von ihrem Bruder oder Schwager aus dem Haus getragen wird, versucht sie sich am Türrahmen des Hauses festzuklammern (Paasonen 1949, S. 62-63). Für den Transport der Braut hat man für den Wagen ein besonderes Verdeck, eine Überdachung, angefertigt (ebd. S. 62).

In allen erwähnten Hochzeitsbeschreibungen wird der Statuswechsel der Braut von einem Mädchen zur Ehefrau durch den Austausch der Kopfbedeckung symbolisiert. Laut Sirotkin hat die Braut mancherorts die Kopfbedeckung einer verheirateten Frau erst nach dem Ehebettritus erhalten (1965, S. 30).

Auffällig an der Beschreibung von Osipov ist, daß die Braut noch im Haus des Bräutigams Brautklagen vorgetragen hat (1985, S. 49). Auch Magnickij berichtet in seiner Hochzeitsbeschreibung aus dem Gebiet Tetjuši, daß noch in der letzten Phase der Hochzeit Angehörige der Braut im Haus des Bräutigams eingetroffen sind und daß sie dort mit Küssen und Brautklagen von der Braut verabschiedet werden. Deshalb hat sie erneut ihr Haupt mit dem großen Tuch bedeckt, der schon der 
Zeremonie gemäß entfernt worden war. Ja, sie weint sogar noch für die Pferde, mit denen sie in das Haus des Bräutigams gebracht worden ist (Magnickij 1881, S. 213).

Laut Osipov ist die tschuwaschische Hochzeitszeremonie nicht in allen Gebieten gleich. Bei den nördlichen Virjaltschuwaschen kennt man ihm zufolge die Brautklage nicht, bei den südlichen Anatritschuwaschen und bei den mittleren Anat-Jenči-Tschuwaschen dagegen gehören die Brautklagen als untrennbarer Teil zur Hochzeitszeremonie (1985, S. 50). Magnickij gibt in einer im Jahre 1881 erschienenen ethnographischen Arbeit eine Osipov entgegengesetzte Information zur Hochzeitszeremonie der Virjaltschuwaschen.

Die Beschreibung der Anfangsphase der Hochzeit ist bei Magnickij äußerst knapp, und die getrennt stattfindenden Feierlichkeiten der Anfangsphase im Heim der Braut und des Bräutigams werden nicht erwähnt. Die Beschreibung des Hochzeitstages beginnt mit einer Schilderung darüber, wie der Bräutigam und sein Geleit im Heim der Braut eintreffen. Wenn der Zeremonienmeister dem Geiger den Befehl gibt zu spielen, beginnt die von ihren Freundinnen umringte Braut zu klagen, sobald sie die ersten Töne vernommen hat (Magnickij 1881, S. 200-).

Die Sprache der Klage ist vom Virjaltschuwaschischen geprägt. Von dem Augenblick angefangen, wo die Braut mit dem Geleit des Bräutigams dessen Heim erreicht, ist die Beschreibung anderen Schilderungen aus dem Anatrigebiet sehr ähnlich. Folglich kann man annehmen, daß die Brautklage erst während der letzten hundert Jahre im Virjalgebiet ausgestorben ist. Man sollte sich auch daran erinnern, daß viele Aufzeichner der tschuwaschischen Tradition uns immer wieder Hinweise darauf geben, daß das Anatrigebiet in vieler Hinsicht die Tradition besser überliefert hat als das nördliche Virjalgebiet.

Auch bei der mischärtatarischen Hochzeit kann man drei verschiedene Phasen unterscheiden: 1. die Brautwerbung und das Entrichten des Brautgelds, 2. die Hochzeit bei der Braut zu Hause und 3. das Überbringen der Braut sowie die Empfangszeremonie, die Hochzeit und das Geleiten der Braut in das Ehebett im Heim des Bräutigams. 
Die Brautwerbung geschah durch einen Brautwerber. Wenn man sich über den Betrag des Brautgelds geeinigt hatte, kam der Vater des Bräutigams mitsamt dem Brautwerber und ein paar älteren Verwandten, um die erste Rate des Brautgelds zu entrichten. Es wurde auch der Tag der zweiten und letzten Rate festgelegt, der sog. Tag der "Vertragshochzeit" (jaras-tuj).

An jenem Tag kam der Vater des Bräutigams erneut mit einem Geleit, zu dem sowohl männliche als auch weibliche Verwandte gehörten. Sie wurden mit Mehlklößchensuppe bewirtet. Die Braut war mit ihren Freundinnen hinter einem Vorhang verborgen oder sie befand sich in einem Zimmer nebenan. Ihr Kopf war mit einem großen Tuch bedeckt. Dorthin kamen die weiblichen Verwandten des Bräutigams, um sie zu begutachten, und dorthin schickte ihre zukünftige Schwiegermutter ihr das Geschenk, einen Ring in einem Teeglas. Danach wurden die Geschenke der Braut an die Verwandten des Bräutigams verteilt. Am selben Abend kamen junge Mädchen aus der Verwandtschaft des Bräutigams in das Haus der Braut, und auch der Bräutigam selbst kam mit seinen Freunden. Diese erwarben für sich den Zutritt zur Gesellschaft der Mädchen und dem Bräutigam das Recht, die Braut einen Augenblick unter vier Augen zu sprechen.

$\mathrm{Zu}$ der Phase vor der Hochzeit im Heim der Braut (der "Trauungs-

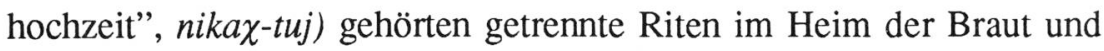
im Heim des Bräutigams. Im Heim des Bräutigams fanden verschiedene Veranstaltungen für Leute verschiedenen Alters und verschiedenen Geschlechts statt. Wenn die alten Männer der Verwandtschaft zusammenkamen, brachten sie ein ganzes Brot mit. Am Essen der jungen Mädchen nahmen auch Mädchen aus der Verwandtschaft der Braut teil. Als rituelle Speise wurde bei diesen Gelegenheiten ein vielschichtiges Gebäck, die Katlamapirogge, gereicht. Als Getränk gab es Bier. Am Hochzeitstag versammelte sich die Verwandtschaft im Heim des Bräutigams. Dann brach sie als Festzug zum Haus der Braut auf; der Bräutigam selbst war nicht dabei.

Die Freundinnen der Braut hatten sich bei dieser gleich nach der Werbung versammelt, um ihr dabei zu helfen, die Mitgift und die Geschenke für die Familie des Bräutigams herzustellen. Sie verließen die Braut in keiner Phase vor der Hochzeit. Sie badeten mit ihr in der sog. 
"Sauna der Braut". Dies geschah in Paaren; zuerst ging die Braut mit ihrer besten Freundin in die Sauna. Zum "Abend des Mädchens" vor dem Hochzeitstag gehörte auch das Besticken des großen Überwurfes ("Bettvorhang"), unter dem die Braut während der Trauungshochzeit mit ihren Freundinnen verweilen sollte und unter dem sie den Bräutigam traf und in sein Heim geleitet wurde - gewöhnlich war der Wagen, auf dem sie fuhr, damit bedeckt -, und im Heim des Bräutigams wurde das Hochzeitsbett damit gleichsam als eigene Behausung abgegrenzt (Muchamedova 1972, S. 168).

Die letzte Nacht in ihrem Elternhaus schlief die Braut fast gar nicht. Sie mußte sogleich im Morgengrauen aufstehen, um die sog. "HahnenRöte-Klage" anzustimmen. Sie machte das Fenster auf, wandte sich gen Osten und begann: "Wird es schon Tag? Gibt es in der Morgenröte Sterne? Ich klage vor dem Morgengrauen. Hat keiner mit mir Mitleid?" Dann geht sie, die Mutter mit der Klage zu wecken: "Steh' auf, Mutter, deine unglückliche Tochter klagt", und nach ihr ist die Reihe an den Freundinnen: "Steht auf, Freundinnen! Klagt die Klage der HahnenRöte meinetwegen! Wir werden bis zum Morgengrauen klagen; wir wollen Glück." Nur die Freundinnen essen das Frühstück, das die Mutter bereitet hat; die Braut klagt weiter. Dann setzen sich die Freundinnen zur Braut, und alle decken sich mit demselben Überwurf ("Bettvorhang”) zu und klagen gemeinsam. In der Klage beschuldigt die Braut ihre Eltern und Angehörigen, die sie angeblich nicht zu Hause behalten wollten, und äußert den Wunsch, schon als Kind gestorben zu sein. Auch Frauen aus dem Dorf, die vorher nicht eingeladen waren, kamen, um die Klagen zu hören; Männer durften sie nicht hören (Muchamedova 1972, S. 161-).

An diesem Hochzeitstag versammelt sich die Verwandtschaft der Braut bei ihr zu Hause, und die Verwandtschaft des Bräutigams kommt ebenfalls als Festzug, allerdings ohne diesen. Der Mullah liest das Hochzeitsgebet. Der Bräutigam ist durch seinen Vater vertreten, und eine bestätigende Antwort wird von der Braut geholt, die mit ihren Freundinnen im selben oder benachbarten Zimmer hinter dem Vorhang sitzt. Sobald die Trauung vorbei war, begann das Festmahl, währenddessen Bier getrunken und gesungen wurde. War die Verwandtschaft der Braut mit dem Lösegeld unzufrieden, sangen die jungen Frauen der 
Sippe Spottlieder. Die Verwandten der Braut luden auch Hochzeitsgäste ein, so daß die Hochzeit drei-vier Tage dauerte.

Der Bräutigam kam mit seinem Geleit erst gegen Ende der Hochzeit. Zunächst ging er jedoch auf den Friedhof, um zu seinen Vorfahren zu beten. Muchamedova betont, daß die Vorfahren sich der Auffassung der Mischärtataren zufolge streng um die Reinheit der Sippe kümmerten. Deshalb war es nötig, sie wegen der Aufnahme einer fremden Frau in die Familie zu besänftigen (Muchamedova 1972, S. 166).

An der Pforte zum Heim der Braut mußte sich der Bräutigam den Eintritt einlösen. Das eine der beiden auf der Treppe wartenden Mädchen brachte die Freunde des Bräutigams zum Festtisch, das andere geleitete ihn selbst zur Braut. Sobald die Freunde gespeist hatten, drängten sie das Brautpaar zum Aufbruch. Die Braut wurde noch zu ihren Eltern gebracht, um ihren Segen zu erhalten. Sie selbst umarmte ihre Eltern und klagte eine Abschiedsklage. Wenn sie fortgeschleift wurde, klammerte sie sich noch an den Türrahmen (a.a.O. S. 166).

Das Überführen der Braut in das Heim des Bräutigams war eine einfache Angelegenheit, da der Bräutigam im selben mit dem Bettvorhang gedeckten Wagen wie die Braut gefahren wurde. Das Bett der Braut war ebenfalls in diesen Wagen geschafft worden (ebd. S. 169).

Die Schwiegermutter und die Frauen der Verwandtschaft des Bräutigams erwarteten die Jungvermählte auf dem Hof vor seinem Elternhaus. Teil dieses Empfanges waren Fruchtbarkeitsmagie und Vorsichtsmaßnahmen. Die Frauen der Verwandtschaft der Braut, die mitgekommen waren, begannen mit dem Ausschmücken des Speichers, in dem sich die Braut und der Bräutigam während der Endphase ihrer Hochzeit hauptsächlich aufhalten würden. Die Schwägerin, die in ihrem Familienleben als glücklichste eingestuft wurde, machte das Hochzeitsbett.

Wenn das Hochzeitspaar in den Speicher gebracht worden war, begann das Hochzeitsfest im Hause selbst. Gewöhnlich gab es zwei Tische; der eine war für die Männer, der andere für die Frauen. Es wurde den ganzen Abend lang gefeiert und auch noch an den darauffolgenden Tagen. In aller Frühe ging das Paar am nächsten Morgen in die Sauna, und erst am selben Tag wurde der Überwurf von der Braut entfernt, so daß alle Gäste es sehen konnten; dies geschah durch einen kleinen Jungen. 
$\mathrm{Zu}$ der Endphase der Hochzeit gehörten außerdem das Etablieren einer Beziehung zwischen der Jungvermählten und dem Ofen und zwischen der Jungvermählten und dem Brunnen oder Fluß (a. a. O. S. 170-).

Muchamedova zufolge ist die mischärtatarische Hochzeit überall außer im Osten des Siedlungsgebietes, im Gebiet Buinsk, eine Klagehochzeit; dort haben die Bräute während der Zeit, in der sie ihre Studien durchführte, keine Brautklagen vorgeführt (Muchamedova 1972, S. 173; S. 181 Anmerkung 38).

Räsänen hat die Hochzeitsbräuche im Gebiet Sergač beschrieben (Räsänen 1945, S. 1-). Anders als bei den von Muchamedova beschriebenen Hochzeitsriten des Gebiets Temnikov gehört bei jenen Mischärtataren keinerlei Auszahlungsfest des Lösegeldes zum Zeremoniell. Sonst sind die gleichen Elemente, die Muchamedova aus ihrem Untersuchungsgebiet schildert, zu erkennen, aber in der entscheidenden Phase ist hier die Situation umgekehrt: Zum Abschluß des Hochzeitsfestes im Heim der Braut werden die Jungvermählten dort in den Speicher geführt, in dem das vorbereitete Hochzeitsbett steht. Räsänen zufolge kann das junge Paar noch wochenlang in seinem Ehebett bei den Eltern der Braut schlafen, bis der Bräutigam die Braut mit ihrer Mitgift endgültig in sein Heim bringt. In den Schilderungen von Räsänen werden keinerlei Brautklagen erwähnt. Auch Muchamedova hat sich mit den Hochzeitsbräuchen des Gebiets Sergač beschäftigt. Bis auf die Beschreibung der Brautklagen stimmt ihr Bericht mit dem von Räsänen überein. Muchamedova betont sogar, daß die Hochzeitsbräuche im Gebiet Sergač sonst mit denen der Kasantataren identisch sind, jene jedoch außerdem die Brautklage kennen. Auch lenkt sie die Aufmerksamkeit darauf, daß der Bräutigam die Braut erst dann zu sich bringen darf, wenn die gesamte Lösegeldsumme entrichtet ist (Muchamedova 1972, S. 173).

Um die Charakteristika der tschuwaschischen und mischärtatarischen Hochzeitsbräuche zu erkennen, muß man zunächst das typische türkische Hochzeitszeremoniell sowie die Riten der Nachbarvölker, der Mordwinen und der Russen, als Ganzes betrachten.

Eine Tatarenhochzeit hat vier Hauptphasen: 1. die Verlobung, 2. die Vermählung und đie Feier im Elternhaus der Braut, 3. der Ehebettritus 
im Heim der Braut und danach eine Phase des Getrenntlebens, während der die Jungvermählte weiterhin bei ihren Eltern und der Bräutigam bei den seinen wohnt, aber seine Frau im Hause ihres Vaters besucht, und 4. der Einzug der Jungvermählten in das Haus des Mannes und die Hochzeitsfeier dort (Tatary srednego Povolž'ja i Priural'ja 235-).

Der Bräutigam nimmt an den ersten beiden Phasen der Hochzeit gar nicht teil. Die Braut nimmt an ihnen passiv teil. Während der Verlobung befindet sie sich in einem anderen Zimmer oder hinter einem Vorhang. Zur Hochzeitsfeier im Heim der Braut kommen die Eltern des Bräutigams und seine männliche Verwandtschaft. Die Trauung wurde von einem Mullah durchgeführt, der Bräutigam war durch seinen Vater vertreten, die Braut $\mathrm{sa} ß$ in einem anderen Zimmer oder hinter einem Vorhang, wohin man um ihre Einwilligung zu fragen kam. Nach dem Festmahl begann das Feiern in den Häusern der Verwandtschaft. Am Tag darauf kamen die Frauen der Verwandtschaft des Bräutigams, die die Braut im anderen Zimmer oder hinter dem Vorhang besichtigen durften. Dann feierten die Frauen ihrerseits in den Häusern der Anverwandten. Am Abend kehrte die Verwandtschaft des Bräutigams heim, am Tag darauf auch seine Eltern.

Während der 3. Phase der Zeremonie, nach der Hochzeit, kommt der Bräutigam zum ersten Mal in das Haus der Braut. Dies geschieht während der Nacht des Donnerstages nach der Hochzeit. Bei der türkischen Zeremonie, wie auch bei der mordwinischen, ist die wahrscheinlich ursprünglich islamische Auffassung von Bedeutung, die Wochentage seien grundlegend verschieden, die einen glücklich, die anderen unglücklich (vgl. Aro 1967, S. 228) oder, der türkischen und mordwinischen Auffassung nach, "schwer" oder "leicht" (Džumagulov 1960, S. 38, Evsev'ev 1966, S. 10). Sowohl an der Pforte als auch an der Tür des Zimmers der Braut muß sich der Bräutigam das Eintrittsrecht erkaufen. Die Braut befindet sich in einem besonderen, eigens hergerichteten Zimmer. Der Bräutigam weilt vier Tage lang bei der Braut. Sie verbringen diese Zeit in ihrem Zimmer, außer daß sie täglich in die Sauna gehen. Beim Aufbruch des Bräutigams kleidet die Braut ihn in ein Hemd und in eine Hose, die sie selbst genäht hat, und gibt ihm Geschenke. Der Bräutigam, oder besser: der Ehemann, kehrt wiederholt zurück, um seine Frau zu besuchen, besonders an Donnerstagabenden. 
Das währt einen Monat, ein halbes Jahr, vielleicht sogar ein Jahr oder noch länger.

Die 4. Phase der Zeremonie wird durch das Überbringen der Braut in das Haus des Bräutigams und ihren Empfang dort repräsentiert. $\mathrm{Zu}$ den Empfangsriten gehört, daß die jungen Frauen aus der Verwandtschaft des Bräutigams kommen, um rituell mit der Jungvermählten zu speisen, und daß sie sie auch zum Wasserholen zum Fluß bringen. Die Eltern der Jungvermählten und ihre männlichen Anverwandten kommen am nächsten Tag zur Hochzeitsfeier im Heim des Ehemannes. Auf die Festlichkeiten im eigenen Heim folgen Feiern bei der Verwandtschaft des Ehemannes. Am Tag darauf kommen auch die weiblichen Verwandten der jungen Frau, und das Feiern wird erneut in den Häusern der Verwandten fortgesetzt. Am Abend gehen die Gäste wieder, am folgenden d.h. dritten Tag auch die Eltern der Jungvermählten, und die Hochzeit ist vorbei (Tatary srednego Povolž'ja i Priural'ja 236-), d.h. das Feiern im Heim des Ehemannes folgt spiegelbildlich dem Muster des Feierns im Heim der Braut.

Als nächstes sollen die mordwinischen - ersanischen und mokschanischen - und die russischen Typen der Klagehochzeit betrachtet werden.

Die ersanische Hochzeitszeremonie teilt sich in drei Phasen: 1. die Werbung und das Entrichten des Lösegeldes, 2. die Hochzeit im Heim der Braut, und 3. die Überführung der Braut in das Heim des Bräutigams mit Zwischenstation in der Kirche sowie das Empfangszeremoniell, das Geleit in das Ehebett und die Festlichkeiten dort. Es ist auch berichtet worden, die Braut sei direkt in das Heim des Bräutigams und erst von dort in die Kirche gebracht worden. Z. B. in Standrovo im Kreis Temnikov im Gouvernement Tambov wurde die Braut am Abend in das Haus des Bräutigams geleitet. Die kirchliche Trauung fand erst am nächsten Tag statt (Fedjanovič 1978, S. 252).

Vor der Brautwerbung besucht man den "reinen Ort" des Hauses, d.h. den Ort, der für die Kontaktaufnahme mit den Vorfahren bestimmt und geheiligt ist (s. z.B. Bartens 1990, S. 112 und die Verweise dort auf weitere Literatur), um zu den Ahnen zu beten (Hämäläinen 1913, S. 241, der sich auf eine Mitteilung von Paasonen beruft). Die Brautwer- 
bung geschieht durch einen Fürsprecher. Dann brechen die Eltern des Bräutigams mit älteren Verwandten auf, um über das Lösegeld zu verhandeln. Nach gelungener Vertragschließung können die zukünftigen Schwiegerväter nach russischer Art Handschuhe anziehen und die Hände zusammenschlagen, wodurch der Vertrag bekräftigt wird.

Die Braut sitzt unter dem Überwurf im Nebenzimmer, in der "Nische". Dorthin schicken ihr ihre Schwiegereltern die Geschenke; die Schwiegermutter Schmuck, mit dem die Braut bei ihnen "vorgemerkt" ist. Die Geschenke der Braut an die Verwandten ihres Bräutigams werden von ihren weiblichen Anverwandten überreicht. Am abgesprochenen Tag bringt der Vater des Bräutigams das Lösegeld in das Heim der Braut - nur ein paar Kopeken werden für die Prozession am Hochzeitstag aufgespart - und der Termin für die Hochzeit wird vereinbart.

Der Bräutigam nimmt also an der ersten Phase der Zeremonie nicht teil. Mancherorts nimmt der ersanische Bräutigam auch nicht an der Hochzeit im Heim der Braut (Evsev'ev 1966, S. 319) und anderenorts sogar nicht einmal an der Feier in seinem eigenen Haus teil. Bei der von Mainoff referierten ersanischen Hochzeit kommt der Bräutigam in die Kirche, in die die Braut nach der Feier in ihrem eigenen Heim gebracht worden ist, aber der Bräutigam verläßt die Kirche sofort nach der Trauung und sucht bei irgendeinem Nachbarn Unterschlupf, bis er am Abend, nachdem die Gäste sein Haus bereits verlassen haben, aufgesucht und in den Speicher gebracht wird, in dem seine junge Frau ihn erwartet (Mainoff 1883, S. 93, 94).

Der zweite Teil der Hochzeitszeremonie beginnt getrennt in beiden Häusern. Der Bräutigam bittet seine Patentante als Brautführerin in seinen Festzug; Evsev'ev zufolge ist eine weibliche Brautführerin eine junge Erscheinung im Festzug des Bräutigams und eindeutig russischer Herkunft, wie schon der Name (svaxa) besagt. Früher gab es keine Frauen im Festzug des Bräutigams (Evsev'ev 1966, S. 95).

Im Haus des Bräutigams hat bereits das Backen des Hochzeitsgebäcks begonnen. Es werden fünf, sieben oder neun Gebäckstücke hergestellt; jedes hat seinen eigenen Namen und seine eigene Funktion. Das größte hat zwölf Schichten, und es wird mit aus Teig geformten Tierfiguren verziert (Evsev'ev 1966, S. 89, Mainoff 1883, S. 81). Dieses Gebäck wird als Ersatz für die Braut deren Familie überlassen und 
von dieser zusammen mit den Verwandten verzehrt, nachdem die Braut mit der Hochzeitsgesellschaft abgereist ist (Evsev'ev a.a. O. S. 90). Die fertigen Gebäckstücke werden im Haus des Bräutigams in den Speicher an jene Stelle gebracht, wo das Hochzeitsbett stehen wird. Dort warten sie bis zum Aufbruch des Hochzeitsgeleits des Bräutigams. Die Frauen, die das Gebäck tragen, imitieren Pferde (a.a.O. S. 94).

Bevor sich der Bräutigam mit seinen Leuten auf den Weg macht, wird er von seinen Eltern gesegnet. Sobald der Festzug zu Pferde aufgebrochen ist, gehen die alten Frauen der Sippe auf die Straße, berichtet Evsev'ev. Sie breiten ein Tuch auf dem Gras aus, bringen auf ihm ein Speiseopfer dar und beginnen, gegen Osten gewandt, die Vorfahren anzuflehen, sie mögen den Festzug auf beiden Wegen beschützen (a. a. O. S. 110). Der heilige Ort, der "reine Ort", konnte früher auch mitten auf der Straße liegen (Harva 1942, S. 70); darum handelt es sich hier offensichtlich.

Im Haus der Braut hat die Braut selbst mit ihren Klagen die Vorbereitung auf die Hochzeit begonnen. In der Nacht, unmittelbar nachdem der Hahn gekräht hat, ist sie an den geheiligten Ort des Hauses gegangen. In ihrer Klage erbittet sie sich von den Ahnen Worte und Tränen, und verkündet den Schutzgeistern des Hauses und der Familie, ja, dem ganzen Dorf, die bevorstehende Trennung; sie wird vernichtet, und deshalb beklagt sie jetzt "mit ihrer Totenklage ihren eigenen Leib".

Danach klagt die Braut jeden Abend bis zum Tag ihrer Hochzeit auf der Vorderbank im Wohnraum (Evsev'ev 1966, S. 10-315). Das Haupt der Braut ist seit der Verlobung bedeckt (Samorodov 1975, S. 25). Auch Frauen aus dem Dorf kommen, um sie klagen zu hören; Männer gehören nicht zum Publikum. Die Klage am Abend vor der Hochzeit ist kurz, weil die Braut bereits um Mitternacht beginnen muß, erneut zu klagen. Sie muß dann so lange ununterbrochen klagen, bis sie ihr Elternhaus verläßt.

In der Nacht, die dem Hochzeitstag vorangeht, begibt sich die Braut erneut nach dem ersten Hahnenschrei aus dem Haus und klagt genauso wie bei Beginn der Brautklage (a.a.O. S. 112).

Am Morgen sucht sich die Braut mit ihren Freundinnen einen Ort, wohin sie vor dem Festzug des Bräutigams - vor den "Nogaiern, Baschkiren" oder vor der "Gewitterwolke" - fliehen kann; Mainoff zu- 
folge weint die Verlobte - seit der Verlobung wird sie maksanka "die Gegebene" genannt -: "Teurer, 1aß mich einen Augenblick mich aufwärmen kommen! Auf meinem Kopf ist eine Gewitterwolke, sie durchnäßt mein schönes weißes Hemd, durchnäßt auch mein seidenes Tuch. Bedecke mich, Teurer, vor der Gewitterwolke! Ich bin meinem Vater nicht mehr recht - er hat mich aus seinem Hause getrieben." (Mainoff 1883, S. 82; vgl. auch S. 91). Der Zufluchtsort ist das Haus des Onkels väterlicherseits oder eines anderen Verwandten des Vaters.

Sobald die Braut in ihr Elternhaus zurückkehrt, beginnt man sie mit dem "Brei des Mädchens" zu füttern: Am Hochzeitstag bringen die Anverwandten Brei in das Haus der Braut - wenn die Verwandtschaft groß ist, können bis zu dreißig Breitöpfe zusammengetragen werden - oder aber das Mädchen macht eine Runde durch die Häuser der Verwandtschaft, um Brei zu essen. Am Hochzeitstag wird auch die "Sauna des Mädchens" oder die "Sauna des Mädchentums" geheizt, wohin die Braut mit ihren Freundinnen geht. Dann bleibt nur noch das Packen der Mitgifttruhe und das Verabschieden von den Freundinnen mit einem Dankesmahl. Danach gehen die Freundinnen hinaus, um auf das Gefolge des Bräutigams zu warten, und die Braut bleibt allein im Wohnraum.

Beim Herannahen des Festzuges eilen die Brautführerinnen zur Braut, um sie zu verschleiern. Diese setzt sich auf die linke Seite, auf die Seite der "Nische", und beginnt mit der Brautklage (Evsev'ev a. a. O. S. 200). Der Festzug des Bräutigams erwirbt sich am Tor den Eintritt und dringt in den Wohnraum ein; das Hochzeitsgebäck, das sie dabei haben, setzen sie auf dem Tisch ab (a.a. O. S. 206). Der Bräutigam sitzt mit der Mütze auf dem Kopf, sagt nichts, tut nur das, was die Brautführerin oder der Zeremonienmeister ihm vorschreibt (a.a. O. S. 97); mancherorts nimmt der Bräutigam an der ganzen Hochzeit nicht teil. Es werden Kerzen vor den Ikonen angezündet, und man betet für das Gelingen der Hochzeit und für das Wohlergehen der Eheleute.

Während das Gebäck auf den Tisch getragen wurde, hat die Braut eine Klage vorgetragen, und während des Gebets singt sie eine zweite Klage. Mit der neuen Klage wendet sie sich an ihre Brüder oder Vettern - von diesen sind zwei schon im Voraus dazu berufen worden - und bittet sie, sie mögen sie vor den "Nogaiern" verstecken. Die beiden tragen sie in den Wagen und fahren sie zum Onkel, wie es abgemacht war. Die 
Brautführerin des Bräutigams singt im Haus der Braut ein Lied über den Weg, den der Festzug des Bräutigams zurückgelegt hat (a. a. O. S. 211-) - dies erinnert an die große Rede des Zeremonienmeisters des Bräutigams der tschuwaschischen Hochzeit, in der dieser ebenfalls die Reise des Festzugs des Bräutigams zum Heim der Braut schildert - und fordert dann den Festzug auf, die Braut zu holen, "entlang den Spuren eines Marders, die markierte Birke zu holen” (a.a. O. S. 215). Bis auf den Bräutigam bricht der Festzug auf. Der Bräutigam bleibt im Haus der Braut zurück.

Im Haus ihres Onkels geht die Braut in die "Nische" oder kriecht im Winter auf den Ofen. Sobald der Festzug des Bräutigams das Haus erreicht, wird er bewirtet, und die Brautführerin und der Zeremonienmeister besuchen die Braut. Das Geleit des Bräutigams kehrt zum Haus der Eltern der Braut zurück, und die Brautführerin erzählt dem Bräutigam, die Braut sei gut.

Nachdem der Festzug das Haus des Onkels wieder verlassen hat, geht die Braut zu ihrer jüngeren Schwester, um dieser ihr "Mädchentum zu übergeben"; das Mädchentum wird durch ein Haarbüschel symbolisiert, das sich die Braut ausgerissen und durch einen Ring gezogen und schließlich mit einem Seidenband umbunden hat. Dieses behält die Schwester in ihr Haar geflochten bis zu ihrer eigenen Hochzeit (Evsev'ev a.a.O. S. 236). Weder bei Mainoff selbst noch bei anderen alten von ihm zitierten Beschreibungen der Hochzeitsriten wird diese symbolische Vererbung "des Mädchentums" erwähnt. Sie gehört zu den russischen Zügen der mordwinischen Hochzeitszeremonie (vgl. Haavio 1933-35, S. 38). Danach entflechten die Brauthelferinnen den Zopf der Braut und klagen dabei selbst. Sie kleiden die Braut mit der Kopfbedeckung und in die Kleidung der verheirateten Frau (a. a. O. S. 247-; vgl. Lehtinen 1979, S. 170).

Es gibt auch andere Überlieferungen davon, wie der Braut die Kopfbedeckung einer verheirateten Frau aufgesetzt wird. Einigen Quellen zufolge geschah dies fünf - sechs Wochen nach der Hochzeit, und im Zusammenhang damit wurde den Schutzgeistern des Hauses und des Hofes und den Vorfahren geopfert. Anderen Quellen zufolge geschah das Aufsetzen dieser Kopfbedeckung Ende des 19. Jahrhunderts nach der kirchlichen Trauung außerhalb der Kirche, und wiederum nach an- 
deren im Haus des Bräutigams entweder nach der Hochzeitsnacht oder gar erst nach Verlauf eines Jahres oder der Geburt des ersten Kindes (Fedjanovič 1978, S. 253).

Danach verläßt die Braut das Haus ihres Onkels und klagt dabei dem Haus Segen (Evsev'ev 1966, S. 249). Die Brüder oder Vettern tragen sie zum Wagen. Sie fährt im Wagen stehend. Um sich hat sie die Brautführerinnen und Freundinnen, die mit ihr klagen, jede in unterschiedlicher Tonlage. Daheim erwartet sie die Mutter der Braut draußen auf der Treppe und führt die Braut, die immer noch klagt, hinein in die "Nische". Von dort wird sie von den alten Frauen der Sippe geholt und zu dem "reinen Ort" geführt, damit sie Abschied von ihren Vorfahren nimmt. Die Opferspeisen setzt man auf den Boden, die Frauen beten, und die Braut klagt halblaut. Es werden Speisereste und Leinenstückchen als Gaben an die Ahnen zurückgelassen.

Zur gleichen Zeit speist der Festzug des Bräutigams im Elternhaus der Braut. Nach dem Essen werden die Geschenke der Braut an den Festzug verteilt; dies geschieht durch die weiblichen Verwandten der Braut. Die Braut selbst befindet sich in der "Nische" und klagt. Dann werden die Geschenke der Braut an ihre Anverwandten verteilt. Diese sitzen paarweise; der Vater und die Mutter auf der Vorderbank bekommen ein Schnapsglas in die rechte Hand und das Geschenk, ein Hemd, in die linke. Die Braut hat sich bis zu ihren Füßen verneigt. Die Eltern geben der Braut Ratschläge, und diese klagt. Die Brautführerin des Bräutigams mahnt den Festzug zur Eile. Die Brüder oder die Vettern bringen die Braut zu ihren Eltern, damit sie ihren Segen empfängt. Die Braut stimmt eine Abschiedsklage an. Sie küßt ihre Eltern, segnet das Elternhaus, den Hof draußen, das Feld. Ein Bruder und ein Vetter tragen sie aus dem Haus in den Wagen. Zumindest im Gebiet von Saransk und Simbirsk ist dieser sowohl in den ersanischen als auch in den mokschanischen Dörfern mit einer Plane bedeckt (Evsev'ev 1966, S. 276-). Mainoff erwähnt häufig diesen bedeckten Wagen, mit dem die Braut in das Haus des Bräutigams transportiert wird (Mainoff 1883, S. 64, 74, $78,96,104)$; dieser wird von den Verwandten des Bräutigams hergestellt (a. a. O. S. 64) oder zumindest bezahlt (a. a. O. S. 104). In dem Augenblick, in dem die Braut aus ihrem Zuhause getragen wird, versucht sie, sich am Türrahmen anzuklammern (in Evsev'evs Bericht 
wird dies nicht erwähnt, dafür aber in mehreren anderen Quellen, z. B. Mainoff 1883, S. 31, 100; UPTMN 6:1, S. 448).

Der Transport der Braut in das Haus des Bräutigams wird so vereinbart, daß ein Abstecher zur Kirche für die Trauung gemacht wird. Die Braut wird bis zum Haus des Bräutigams von ihren Brüdern oder Vettern und ihren Brautführerinnen begleitet. Die Braut klagt eine Brautklage, während sie in das Haus geführt wird, und wieder im Wohnraum, wo sie vor den Ofen gesetzt wird. Gebietsweise - Evsev'ev zufolge im Gouvernement Simbirsk - begleiten die eigenen Verwandten die Braut nur auf eine Entfernung von einer halben Werst von ihrem Heimatdorf. Dort macht der Wagen halt, die Braut steigt herab und beginnt, sich mit einer Klage bei den Pferden $\mathrm{zu}$ bedanken, vor denen sie niederkniet (Evsev'ev 1966, S. 274). Zugleich kommt der Festzug des Bräutigams an. Der Bräutigam springt von seinem Wagen herunter, packt die Braut und setzt sie sich mithilfe seines Zeremonienmeisters in seinen eigenen Wagen. Die Braut verabschiedet sich mit Klagen bei ihrem Geleit. Sobald sie mit ihrer neuen Verwandtschaft allein gelassen worden ist, hört die Braut auf zu klagen (a.a. O. S. 275).

Dieselbe Beobachtung der Übergabe der Braut auf halbem Wege ist in der alten Hochzeitsbeschreibung von Lepechin enthalten, die über die Ersanen des Dorfes Čeremašna im Gebiet Stavropol in dem Gouvernement Simbirsk verfaßt worden ist (von Mainoff referiert: Mainoff 1883, S. 30); zu Mainoffs Zeiten hatten sich die Ersanen des Gebietes schon gänzlich mit den Russen assimiliert. Auch in Mainoffs eigener Schilderung wird die Braut an der Dorfgrenze übergeben (Mainoff 1883, S. 101-; die Braut widmet den Pferden eine Klage). Die neueren Schilderungen (UPTMN 6:1) wiederum kennen die Übergabe der Braut an der Dorfgrenze nicht. Grund dafür ist entweder, daß sie aus jüngerer Zeit stammen, oder daß sie größtenteils aus westlicheren Gebieten, im Gebiet der Mordwinischen Republik, aufgezeichnet worden sind.

Im Haus des Bräutigams wird die Braut von ihren Schwiegereltern empfangen. Fruchtbarkeits- und Schutzmagie gehören zu den Riten. Im Wohnraum wird die Braut zum Ofen geleitet (vgl. Fedjanovič 1978, S. 253-). Die Frauen der Verwandtschaft des Bräutigams haben im Speicher ein Hochzeitsbett hergerichtet. Die alten Frauen beten dort für 
das Paar um "sieben Söhne, sieben Töchter" und imitieren Pferde, stampfen mit den Füßen und wiehern (Evsev'ev 1966, S. 286).

Dann kommt die Verwandtschaft der Braut, um im Haus des Bräutigams zu feiern. Getrennte Tische werden für Männer und Frauen aufgestellt (a.a. O. S. 294). Die Verwandtschaft der Braut verlangt, sie zu Gesicht zu bekommen ("wir kamen auf Mardersspuren", a. a. O. S. 296). Das Paar wird aus dem Speicher herbeigeholt, und erneut imitieren die Frauen Pferde. Erst jetzt wird der Braut zeremoniell das Tuch abgenommen; dies wird von einem Jungen getan. Danach verteilt die junge Frau ihre Geschenke an die Anverwandten des Mannes. Die Schwiegereltern geben ihr ihrerseits Ratschläge.

Am nächsten Tag führen die alten Frauen der Sippe des Bräutigams die Jungvermählte an den "reinen Ort", damit sie den Vorfahren des Bräutigams vorgestellt werden kann. Sie haben Essen und Leinenstücke als Geschenke für die Ahnen dabei (zu früheren Zeiten wurden ganze Kleidungsstücke statt Stoffstücken verwendet). Eine der Frauen spricht ein Gebet. Die Jungvermählte schweigt. Dann wird die junge Frau auf ähnliche Art und Weise den Schutzgeistern des Hofes und des Brunnens vorgestellt, die von ihr Kupferringe erhalten (Evsev'ev a.a. O. S. 303).

Am selben Tag kehren die Verwandten der Braut nach dem Essen nach Hause zurück. Am dritten Tag opfert die junge Frau dem Hausgeist der Familie ihres Mannes Gebäck, das sie von zu Hause mitgebracht hat. Darauf löst sich auch die Hochzeitsgesellschaft des Bräutigams auf. Die Hochzeitsfeierlichkeiten sind beendet.

Die mokschanische Hochzeitszeremonie unterscheidet sich nicht wesentlich von der ersanischen (vgl. z. B. UPTMN 6:2, S. 42-135). Jedoch wird die Abwesenheit des Bräutigams während der Anfangsphase der Hochzeit und der Feier im Haus der Braut häufiger erwähnt (z. B. Mainoff 1883, S. 31, 72, 74, 105). Schon nach Mainoff und später nach Samorodov erklären sich die Unterschiede in den Riten von Ersanen und Mokschanen dadurch, daß irgendein Charakteristikum, irgendeine Phase bei den einen oder anderen in Vergessenheit geraten ist (Mainoff 1883, S. 96; Samorodov 1975, S. 17-).Im mokschanischen Gebiet ist z. B. bis vor kurzem der Ritus bekannt gewesen, durch den die Braut einen neuen Namen erhält: Die junge Frau, die nach ihrer Verlobung lediglich "die Gegebene" gewesen war, erhielt im Hause des Bräu- 
tigams einen Namen, der ihre Stellung unter den Schwiegertöchtern des Hauses widerspiegelte; im ersanischen Gebiet war diese Sitte schon vor hundert Jahre zu Evsev'evs Zeiten nahezu in Vergessenheit geraten (Samorodov 1975, S. 17).

Der Anteil der Brautklagen ist bei der mokschanischen Hochzeit geringer, der der Lieder, vor allem der Spottlieder, dafür entsprechend größer (a.a. O. S. 17-). Die abendlichen Klagen der Braut sind schon vor langer Zeit fast gänzlich in Vergessenheit geraten (a.a. O. S. 18). Gewöhnlich hat die mokschanische Braut im Wohnraum geklagt und dazu eine Person gehabt, die sie zum Klagen bringen sollte (z. B. UPTMN 6:2 62, S. 156). Einer Schilderung zufolge geht die Braut hinaus zum "reinen Ort", um dort zu klagen (UPTMN 6:2, S. 96-). Die Braut beginnt mit dem Klagen meist nach der Bestätigung der Verlobung (UPTMN 6:2, S. 28, 62; vgl. auch S. 46, 143, 217). Jedoch beginnt die mokschanische Braut in den älteren Berichten von Paasonen und Evsev'ev erst am Hochzeitstag mit dem Klagen.

Es ist die Schwägerin, die mit der Klage beginnt, die Braut nimmt dann die Klage auf. In den alten Schilderungen wendet sich die mokschanische Braut in diesem ersten Klagelied auch an ihre Vorfahren, indem sie jene um Worte und Tränen bittet und dabei fast wörtlich auf dieselben Formeln zurückgreift, wie die ersanische Braut (Paasonen 1947, S. 513; Evsev'ev 1966, S. 430-). Das späte Beginnen der Klagelieder läßt sich dadurch erklären, daß das Lösegeld der mokschanischen Braut oft erst am Hochzeitstag bezahlt wurde (Mainoff 1883, S. 106; Hämäläinen 1913, S. 55; Bartens 1990, S. 114-).

Den Kopfschmuck einer verheirateten Frau erhielt die mokschanische Braut somit auch erst im Haus des Bräutigams (Fedjanovič 1978, S. 253). Außerdem kann zu einer Hochzeit auf mokschanischem Gebiet jüngeren Berichten zufolge ein "Inspizieren des Hauses des Bräutigams" in der Zeit zwischen Verlobung und Hochzeit gehören, wozu die Eltern und Anverwandten des Bräutigams die entsprechenden Familienmitglieder der Braut einladen (UPTMN 6:2, S. 146-). Dies scheint offensichtliches Leihgut von russischen Hochzeiten zu sein.

Der folgenden Beschreibung einer russischen Hochzeit liegt eine Schilderung der nordrussischen Hochzeit von Čistov zugrunde (Čistov 1981, 
S. 115-131). Sowohl das Siedlungsgebiet der Tschuwaschen als auch der Mischärtataren ist in dem von Čistov umrissenen nordrussischen Kulturkreis inbegriffen (a.a. O. S. 111-). Čistovs Ansicht nach ist der nordrussische Kulturkreis im 12.-17. Jahrhundert entstanden (a. a. O. S. 113); das zuletzt hinzugekommene Gebiet ist gerade die Region der Tschuwaschen und der Mischärtataren, die bis Mitte des 16. Jahrhunderts zum Khanat von Kasan gehörte.

Bei der nordrussischen Hochzeit kann man ebenfalls drei Phasen unterscheiden: 1. die Werbung und die Aushandlung von Verträgen, 2. die Vorbereitungen der Hochzeit und die Feier im Haus der Braut, und 3. das Überbringen der Braut in das Haus des Bräutigams via Kirche, die Empfangsriten und das Geleit ins Bett.

Die Werbung geschieht durch den Brautwerber und den Vater des Bräutigams, mancherorts auch durch den Bräutigam selbst oder durch den Brautwerber allein. Für die Braut wurde keinerlei Lösegeld entrichtet, aber die Verwandtschaft des Bräutigams beteiligte sich auch an den durch die Hochzeit entstandenen Kosten. Die Verlobung wurde durch den Handschlag der Schwiegerväter bei einer gesonderten Gelegenheit bestätigt. Auch hier begutachtete die Verwandtschaft der Braut im voraus das Heim und den Haushalt des Bräutigams, und die Familien organisierten Gelegenheiten, bei denen sich die jungen Leute öffentlich treffen konnten (Čistov 1981, S. 115-). Im Gebiet Wolodga z. B. besuchte der Bräutigam am Wochenende vor der Hochzeit seine Braut, um ihr seine Geschenke zu bringen. Die Braut weinte und bat, daß der "vollkommen Unbekannte" von seinen Heiratsabsichten absehe, und fragte, ob sie Geschenke von ihm annehmen könne (Balašov - Marčenko - Kalmykova 1985, S. 100).

Die Freundinnen der sich auf die Hochzeit vorbereitenden Braut versammeln sich in ihrem Haus, um ihr bei der Herstellung der Mitgift und der Geschenke an die Verwandtschaft des Bräutigams behilflich zu sein. Die Braut ging auch bei den Verwandten von Haus zu Haus, um sie zur Hochzeit einzuladen und um sich von ihnen zu verabschieden.

Mit den Brautklagen hat die Braut gleich nach der Verlobung begonnen und bis zu ihrem Hochzeitstag und dem Aufbruch aus dem elterlichen Haus geklagt. Bevor die Braut mit dem Klagen begann, wurde ihr Haupt bedeckt. Das taten gewöhnlich ältere Frauen, aber es konnte 
auch durch Freundinnen oder eventuell sogar durch den Vater oder den Bruder geschehen. Die Braut behielt das Tuch bis zu ihrem Hochzeitstag um und nahm es nicht einmal während der Nacht ab (Balašov Marčenko - Kalmykova 1985, S. 34-).

Vor der Hochzeit unterrichteten die bereits verheirateten Frauen die Braut im Klagen. Es wurde als eine Schande angesehen, wenn die Braut keine Klagelieder kannte (Čistov 1981, S. 117). Es gibt jedoch Daten über den Rückgriff auf eine oder sogar mehrere Frauen, die die Braut zum Klagen bringen sollten. Kruglov, der Erforscher der russischen Brautklage, den Konkka zitiert, sagt sogar: "Wir können jeden beliebigen Bericht über die Hochzeitsbräuche des 19. Jahrhunderts zu Rate ziehen, um uns davon zu überzeugen, daß die Braut nicht allein klagte" (Konkka 1985, S. 110).

Zumindest im Gebiet Wolodga verließ die Braut am Abend das Haus mit ihren Freundinnen, um auf der Anhöhe Klagelieder zu singen, und zwar eine ganze Woche lang vor der Hochzeit (Balašov - Marčenko - Kalmykova 1985, S. 48-). Lupinskaja und Safjanova, die die Hochzeitsbräuche der Russen im Altai-Gebiet untersucht haben, berichten, die Freundinnen hätten die Braut während der Zeit zwischen der Verlobung und der Hochzeit jeden Morgen bei erster Morgenröte auf den Hof oder die Straße geführt, wo die Braut klagte: "Da habt ihr lieben Freundinnen mich vor eine weiße Morgenröte gebracht!" Der Brauch, "die Morgenröte zu schlagen, zum Erdröhnen zu bringen" (otbivanija zor), ist den Autorinnen zufolge auch in manchen Gebieten auf europäischer Seite bekannt (Lupinskaja - Safjanova 1978, S. 191). Auch fremde Frauen kamen aus dem Dorf, um die Klagen zu hören; daß Männer sie hörten, wurde für unpassend gehalten (Balašov - Marčenko - Kalmykova 1985, S. 46). Allerdings trug die Braut ihrem Bräutigam wie auch ihren männlichen Anverwandten ihre Klagelieder vor (a.a. O. S. 100).

Die Braut verbringt den Abend vor der Hochzeit, dessen Name von dem Wort, das 'Mädchen' bedeutet, abgeleitet ist, mit ihren Freundinnen. Die Braut gibt ihr "Mädchentum" unter Klagen auf und vererbt es symbolisch einer jüngeren Schwester oder Freundin. In den meisten Gebieten wird dies durch das Zopfhalterband eines Mädchenzopfes symbolisiert (Čistov 1981, S. 120). Mancherorts hat sich die Braut von 
ihrem Mädchentum, ihrer "Schönheit", krasota, erst in dem Augenblick getrennt, in dem sie dabei ist, das Haus mit der Hochzeitsgesellschaft ihres Bräutigams zu verlassen, bevor sie ihr Vater an den Tisch neben den Bräutigam führt (Balašov - Marčenko - Kalmykova 1985, S. 218-, 361, 362). Zum Abend vor der Hochzeit gehörte außerdem ein Saunabesuch der Braut mit ihren Freundinnen, bei dem Klagelieder ertönten. Mancherorts fand der Saunabesuch schon früher statt, andernorts erst am Morgen des Hochzeitstages.

An jenem Morgen ist die Braut mit einem Klagelied geweckt worden. Die weckende Person ist gewöhnlich die Patin oder die Mutter, und sie erklärt, der Hahn habe schon gekräht und der Morgen graue (Razumova - Koski 1980, S. 23-, 25). Den Hochzeitsbräuchen der russischen Bevölkerungsgruppen der Ukraine zufolge mußte die Braut wiederum ihre Freundinnen am Hochzeitsmorgen mit einem Klagelied wecken: "Steht auf, Freundinnen! Schon rötet sich der Himmel. Die Vertreiber beraten unter sich, sie wollen mich von meinem eigenen Vater, von meiner eigenen Mutter trennen!" (Čižikova 1978, S. 169).

Bei der Ankunft des Festzuges des Bräutigams am Gehöft der Braut mußten sie sich an der Pforte den Eintritt erfeilschen. Vom Bräutigam und vom Zeremonienmeister verlangten die Freundinnen noch im Wohnraum ein Geld, mit dem sich die beiden den Gang an die Hochzeitstafel freikauften.

Die Braut hielt sich in der "Nische" neben dem Ofen auf, aus der sie zum Betrachten geholt wurde. Es konnte geschehen, daß sie zweimal geholt wurde. Beim ersten Mal kam sie in ihrem Hochzeitsgewand heraus, und man gab ihr ein Tablett in die Hand, auf dem sie den Gästen Getränke servierte. Dann kehrte sie in die "Nische" zurück und trat später in einem neuen Festkleid hervor. Vom Vater geholt und an den Tisch geführt, setzte sie sich neben den Bräutigam. Die Braut und der Bräutigam selbst aßen nichts. Vor dem Aufbruch segneten die Eltern der Braut die jungen Leute, und die Braut verabschiedete sich mit Klageliedern von den Ihrigen. Der Bräutigam trug sie in den Schlitten oder auf den Wagen und setzte sie neben den Brautführer. Selbst fuhr er in einem anderen Schlitten. Manchmal verabschiedete sich die Braut mit einem Klagelied noch vom Hof des elterlichen Hauses. Bei der Kirche trug der Bräutigam sie wieder hinein und heraus. Es kam vor, daß man der Braut 
nach der Trauung gleich außerhalb der Kirche die Haare zu zwei Zöpfen, zur Haartracht einer verheirateten Frau, flocht und sie mit der Kopfbedeckung einer verheirateten Frau bedeckte (Čistov 1981, S. 121-).

Im Hause des Bräutigams bereiteten dessen Eltern den Empfang vor. $\mathrm{Zu}$ den Empfangsriten gehörte auch Fruchtbarkeitsmagie. Das Tuch wurde zeremoniell vom Haupt der Jungvermählten entfernt (a. a. O. S. 123); im Gebiet Wologda war es der Schwiegervater, der ihr das Tuch abnahm (Balašov - Marčenko - Kalmykova a. a. O. 295). Die Eheleute wurden in das Hochzeitsbett im Speicher geführt, und die Hochzeitsgäste setzten sich an die Festtafel. Am Morgen weckten sie das junge Paar mit Gesang. Die junge Frau mußte nun ihre ersten Hausarbeiten verrichten, während alle zusahen; ihre Geduld wurde durch spielerisches Stören auf die Probe gestellt (Čistov 1981, S. 122-).

Wenn man diese fünf Hochzeitszeremonien, die tschuwaschische, die mischärtatarische, die kasantatarische, die mordwinische und die nordrussische, vergleicht, muß die erste grundlegende Trennlinie zwischen den Bräuchen der Kasantataren und denen der anderen gezogen werden. Bei der kasantatarischen Zeremonie gibt es nämlich eine Phase mehr als bei den anderen: Zwischen der Hochzeitsfeier im Haus der Braut und der im Haus des Bräutigams liegt eine Zeit, in der das Paar getrennt lebt, d.h. die junge Frau wohnt weiterhin im Hause ihres Vaters, und der Ehemann bleibt bei seinen Eltern, obwohl er die Braut in ihrem elterlichen Zuhause besucht. Diese Phase beginnt mit dem Bettritus, der also im Haus der Braut durchgeführt wird. Bei den anderen vier Traditionen gehört der Bettritus zu dem Teil der Zeremonie, der im Haus des Bräutigams stattfindet.

Cistov spricht von zwei typologischen Konstruktionsschemata, wobei das zentralasiatische in bezug auf die Frau, das osteuropäische in bezug auf den Mann lokalisiert ist: "Bei einer uxorlokalen Hochzeit wird der Bettritus auf dem Gebiet der Familie der Braut vollzogen, bevor diese sie verläßt und in das Haus der Familie des Ehemannes einzieht. Auf jeden Fall liegt der Aufbruch zeitlich nach dem Bettritus. Sollte die Braut unmittelbar nach der Hochzeit zum Bräutigam gehen, kehrt sie gewöhnlich bald zu ihren Eltern zurück und zieht erst später (einige Tage vor ihrer ersten Niederkunft) endgültig ins Haus (in die 
Jurte) ihres Ehemannes ein, wo sie lange ihre neuen Verwandten vermeidet, besonders die männlichen Geschlechts. Die wichtigsten Riten, die die Heirat sanktionieren, werden auf dem Gebiet der Eltern der Braut vollzogen. Der Bräutigam und die Braut nehmen an ihnen nicht teil, sondern "verstecken sich" (die Braut im "Ehegebäude" und der Bräutigam bei Nachbarn oder Verwandten).

Charakteristisch für den europäischen virilokalen Typus ist der Vollzug des Bettritus auf dem Gebiet der Familie des Bräutigams, sobald die Braut ihr Zuhause verlassen hat und im Haus des Bräutigams empfangen worden ist. Der Umzug findet also vor dem Bettritus statt und sowohl der Bräutigam als auch die Braut nehmen an allen Riten teil, auch an der Hochzeitsfeier.

Die Uxorlokalität des zentralasiatisch-kaukasischen Ritus im $\mathrm{Zu}$ sammenhang mit der vorübergehenden Uxorlokalität der eigentlichen Ehe kommt besonders bei den Nomaden- und Halbnomadenvölkern sowie bei archaischen Jägern und Sammlern vor. Daraus folgt, daß der uxorlokale Ritus vor allem bei den Völkern dem virilokalen vorangegangen sein kann, die von der Viehwirtschaft zum seßhaften Anbau übergegangen sind." (Čistov 1981, S. 129-).

Die Brautklage folgt derselben Grenze der uxor- und virilokalen Tradition: Sie ist der uxorlokalen kasantatarischen Zeremonie nicht bekannt. Die Verbindung zwischen dem Ort des Bettritus und der Brautklage wird in den Beschreibungen mischärtatarischer Hochzeitsbräuche besonders deutlich: In der Beschreibung von Muchamedova aus dem Gebiet Temnikov wird die Braut ins Elternhaus des Bräutigams gebracht und dort ins Hochzeitsbett geleitet. Im Bericht von Räsänen aus dem Gebiet Sergač wird das junge Paar im Heim der Braut in das Ehebett geführt, bevor die Braut mit der Hochzeitsgesellschaft des Bräutigams in seinem Haus einzieht; von dort kehrt das Brautpaar während mehrerer Wochen in das Haus der Eltern der Braut zurück, um im dort gebliebenen Bett zu schlafen. Die Braut des von Muchamedova beschriebenen Ritus klagt, diejenige aus Räsänens Bericht nicht (Muchamedovas allem Anschein nach spätere Beobachtungen aus dem Gebiet Sergač stehen im Widerspruch dazu.)

Hinter der Verbindung zwischen Bettritus und Brautklage muß die Form der Ehe an sich verborgen sein. Džumagulov spricht von matri- 
lokaler und patrilokaler Ehe. Er nimmt an, daß die kirgisische Brautklage in der Zeit entstanden ist, als man "von matrilokaler zu patrilokaler Ehe überging" (Džumagulov 1960, S. 39). Er hat mündlich überlieferte Quellen dazu aufgezeichnet, daß ein junges kirgisisches Ehepaar früher im Haus des Vaters der Braut das Eheleben aufnahm - tatsächlich handelt es sich also um eine vorübergehende uxorlokale Ehe -, bis der Brauch nicht mehr aufrechterhalten wurde und das Eheleben dann nur noch im Haus des Vaters des Bräutigams begonnen wurde (a.a. O. S. 38).

Sogar eine vorläufige uxorlokale Ehe macht also die Klagelieder überflüssig; der Grund dafür mag sein, daß die Braut weiterhin bei ihrer Sippe bleibt. Die Trennung von der Verwandtschaft geschieht nicht plötzlich. Die vorübergehende uxorlokale Ehe hat gewöhnlich bis zu den letzten Tagen vor der Geburt des Kindes bestanden (Čistov 1981, S. 129). Weil die junge Frau schon durch die Geburt ihres Kindes ein Mitglied der Familie ihres Mannes wird, hat ihre eigene Verwandtschaft einschließlich ihrer Vorfahren anscheinend wenig Einfluß mehr auf sie.

Dieser Übergang in die Familie des Mannes durch das Kind ist problemlos im Hinblick auf die jüngeren Mitglieder der Verwandtschaft, während das Verhältnis zu den älteren Mitgliedern einschließlich der Ahnen nicht reibungslos ist. Džumagulov berichtet, daß die Frauen der Verwandtschaft des Bräutigams der kirgisischen Braut entgegeneilten, sobald sie sich dem Haus nähere; sie nähmen ihr die Kopfbedeckung ab und bedeckten ihr Haupt mit einem großen Tuch, so daß nichts vom Gesicht sichtbar bleibe. Die junge Frau habe ihr Gesicht nie ihren Schwiegereltern oder anderen älteren Verwandten ihres Mannes zeigen dürfen, auf keinen Fall vor der Geburt ihres ersten Kindes (Džumagulov 1960, S. 40-). Die tschuwaschische Jungvermählte mußte ebenso wie die Mordwinin darauf achten, daß sie ihrem Schwiegervater und den älteren Männern der Sippe des Mannes nie ihre Haare oder ihre nackten Füße zeigte (Paasonen 1949, S. 68).

Bei der virilokalen Zeremonie und Ehe, in der die Braut sofort auf das Gebiet der Familie des Mannes gebracht wird, gibt es zwar Spannungen zwischen ihr und der Verwandtschaft ihres Mannes (bevor der mischärtatarische Bräutigam seine Braut zu sich holt, betet er zu seinen Vorfahren, weil es der Beschwichtigung der Ahnen bedarf, wenn eine fremde Frau in die Sippe geholt wird: Muchamedova 1972, S. 166), 
aber der größte Zwiespalt tut sich zwischen der Braut und ihrer Familie, ihren eigenen Vorfahren auf, die sie im Begriff ist zu verlassen.

Um in eine fremde Sippe überwechseln, unter neuen Verwandten geboren werden zu können (die Chakassen nennen die Jungvermählte ein "neues Kind" - Gemuev 1989, S. 194), muß die Braut in ihrer alten Sippe sterben. Die Türkvölker des Altai-Gebietes sprechen von den drei Vermählungen des Menschen: der Geburt, der Hochzeit und dem Tod (a.a. O. S. 219). Man könnte von einer entsprechenden Auffassung der Wotjaken annehmen, sie sei ebenfalls türkisch (Vladykin - C̆urakova 1986, S. 108), aber auch die Ostseefinnen haben die Hochzeit mit dem Tod assoziiert (Konkka 1985, S. 181), und dieselbe Übergangsphase von jeweils sechs Wochen gehört nicht nur zur Geburt und zur Heirat, sondern auch zum Tod (a. a. O. 183). Der Überwurf, den die türkische Braut in Südsibirien über sich ausgebreitet bekommt, stellt eine konkrete Metapher des Todes dar: "Im traditionellen Bewußtsein, das nach dem Äußeren orientiert war, nach dem, was sichtbar war, wurde ein symbolisches oder reales Verschwinden aus dem Blickfeld mit einem zumindest vorübergehenden Tod gleichgesetzt" (Gemuev 1989, S. 194). Auch im virilokalen Ritus tritt die Braut bedeckt, durch den Tod, in die neue Familie ein. Andererseits ist das Verschleiern der Braut in manchen Traditionen auch eine Vorsichtsmaßnahme, mit der man die Braut vor bösen Kräften schützen will (Hämäläinen 1913, S. 232-), und dieser Aspekt ist sicher auch in der Bedingung der Finnougrier, aber auch der Slawen und der Türkvölker enthalten, daß die Braut verschleiert sein muß, wie Hämäläinen denn auch in seiner Untersuchung annimmt.

In dem Gebiet, das sich vom Baltikum bis zum Ural erstreckt, und wo die Braut mit einem virilokalen Ritus in die neue Sippe eintritt, ist diese jedoch nicht passiv wie ein Toter, sondern trägt ihre Brautklagen selbst vor. Sie bricht ihre Bande mit den Eltern und den Vorfahren. Sie beherrscht den entstehenden Konflikt mit ihren Klagen. Die Tatsache, daß durch die Klagelieder wirklich Kontakt mit dem Totenreich, mit den Vorfahren aufgenommen wird, zeigt sich konkret eben in der Verschleierungsforderung. Die Braut, die Klagelieder singt, muß verschleiert sein. Diese Bedingung existiert in allen vier oben beschriebenen Traditionen. (Ein Musterbeispiel ist das Verhalten einer tschuwaschischen Braut, wie es von Magnickij beschrieben wurde: Wenn die 
Jungvermählte in ihrem neuen Heim wieder zu klagen beginnt, bedeckt sie sich erneut mit dem großen Tuch, der ihr bereits zeremoniell abgenommen worden war.)

Konkka meint in ihrer Untersuchung zu den karelischen Klageliedern, die Brautklage sei aus dem Bemühen entstanden, die Gemüter der Ahnen zu besänftigen (Konkka 1985, S. 182). Auch Hämäläinen ist von der Funktion der Brautklage ausgegangen, den Verstorbenen der Sippe und gleichzeitig den Schutzgeistern des Hauses zu zeigen, wie schwer einem der Abschied fällt, und sie dabei wieder gnädig zu stimmen (Hämäläinen 1913, S. 242). Den Ursprung der mordwinischen Brautklage kann man ebenfalls in der Kontaktaufnahme zu den Vorfahren vermuten (Bartens 1990, S. 104-). Konkka fragt in ihrer Studie, ob es der Beschwichtigung der Ahnen vielleicht deshalb bedurfte, weil man gegen das alte Ehesystem verstoßen hatte. Sie verweist auf die Heirat zwischen Cousins, die in Nord- und Zentralasien bekannt war, und bei der der Mann normalerweise die Tochter seines Onkels mütterlicherseits geheiratet hatte (Konkka 1985, S. 182). Z. B. der Auffassung der Kirgisen nach handelt es sich in solchen Fällen nicht um Verwandtschaft; dagegen durfte man eine Frau aus der Verwandtschaft des Vaters erst nach sieben Generationen heiraten - eine weit verbreitete Forderung bei den Türkvölkern (Džumagulov 1960, S. 27). Die allgemeine Formel der tschuwaschischen Hochzeitsfolklore von "sieben Fremden" basiert offensichtlich darauf.

Der Zusammenhang zwischen dem Ort des Bettritus und der Brautklage veranlaßt uns, wie Džumagulov anzunehmen, die Brautklage sei beim Übergang von einer (oft nur vorübergehenden) uxorlokalen Ehe der Nomaden und Halbnomaden oder der Jäger und Sammler zu einer virilokalen Ehe (vgl. oben das Zitat aus Čistovs Arbeit) in einer solchen Gesellschaft entstanden, wo der Ahnenkult und die Auffassung von der Kontinuität des Kontaktes zwischen den Sippenmitgliedern über den Tod hinaus eine grundlegende Komponente der Weltanschauung gewesen ist. Jene Stellung hatte der Ahnenkult sowohl in der Weltanschauung der Türkvölker (Harva 1933, S. 247) als auch der Finnougrier (Harva 1964, S. 60-, 73) und der slawischen Völker inne (Máchal 1918, S. 233-, 239). 
Charakteristika, die besonders auf den Ahnenkult verweisen, gab es besonders in der Beschreibung einer mordwinischen Hochzeit unter den fünf Schilderungen oben im Text. Außer daß die mordwinische Braut ihre Vorfahren um Worte und Tränen für ihre Klagen bittet, verabschiedet sie sich ja auch beim Verlassen ihres Zuhauses zunächst von den Vorfahren. Im neuen Heim wird sie dann als erstes den Vorfahren ihres Mannes vorgestellt. Wenn der mordwinische Bräutigam aufbricht, um seine Braut nach Hause zu holen, sind es die Vorfahren, um deren Unterstützung er für sein Unternehmen bittet; sogar vor der Brautwerbung ist zuerst der Rat der Ahnen eingeholt worden. (Es ist auffällig, daß die alten Mitglieder der Verwandtschaft, die die Ahnen anflehen, immer Frauen sind, sei es, wenn die Braut ihr altes Zuhause verläßt und ihr neues bezieht, sei es, wenn der Bräutigam mit seiner Gesellschaft aufbricht. Harva bemerkt, daß sogar bei den mordwinischen Gedenkfeiern für die Toten die Gebete stets von einer Frau, einer Witwe, gesprochen wurden: Harva 1942, S. 263. Die Rolle der Frau ist also in der mordwinischen Kultur auch über das Vortragen von Klageliedern hinaus als Aufrechterhalterin des Ahnenkultes wichtig gewesen.)

Auch bei der tschuwaschischen Hochzeit wird sowohl im Haus der Braut als auch beim Bräutigam betont, daß die Hochzeitszeremonie einer von den Ahnen festgesetzten Sitte folgt. Die Braut geht selbst, um die Ahnen um ihren Segen zu bitten. Der mischärtatarische Bräutigam betet die Vorfahren an, bevor er es wagt, eine fremde Frau in seine Verwandtschaft zu bringen.

Bei einer russischen Hochzeit scheint die Verbindung zum Jenseits, zu den Ahnen, schwächer. Wenn der Ahnenkult und der Kult der Schutzgeister des Hauses zusammengelegt werden können, gibt es einen Zusammenhang: "Die Braut muß einerseits von den Göttern ihrer Familie vor der Heimführung Abschied nehmen und andererseits sich den Schutz der Götter der Bräutigamsfamilie bei ihrer Ankunft im Bräutigamshaus erflehen" (Balys 1946, S. 63 beruft sich auf eine Mitteilung von J. Piprek). Wenn die Braut Waise ist, klagt sie auch am Grab ihrer Eltern (z. B. Balašov - Marčenko - Kalmykova 1985, S. 49-) - der Hochzeitszeremonie ist also eine Totenklage beigefügt (vgl. Čistov 1982, S. 105-), aber einen Ahnenkult macht dieses noch nicht aus. Im Wologda-Gebiet geht die Braut abends hinaus, um auf 
einer Anhöhe zu klagen, was ich für eine Entlehnung aus der mordwinischen Kulturzone gehalten habe (Bartens 1990, S. 116-); bei der russischen Zeremonie ist die Funktion dieser Handlung verlorengegangen. Auch beim morgendlichen Gang der russischen Braut mit ihren Freundinnen, um "die Morgenröte zu schlagen", scheint es sich um einen direkten Einfluß der mordwinischen Tradition zu handeln. In der Beschreibung einer mordwinischen Hochzeit von Sachmatov klagt die Braut am Anfang ihres ersten Klageliedes im Morgengrauen: "Ich schlage die Glocke. Ich schlage vom Boden aufwärts: zu der gesamten Verwandtschaft, zu der gesamten Sippe. Ich schlage zurück auf den Boden: zu den Toten, zu den Ahnen. Hört mich, ihr Ahnen!" (Sachmatov 1910, S. 241-). Es handelt sich nicht um eine Metapher. Bojarkin gibt an, die Braut habe in der Tat eine Glocke bei dieser frühen Klage verwendet; sie gab Signale damit (Bojarkin 1986, S. 42-. Das Gießen von Glocken begann in Asien. Die älteste erhaltene Glocke wurde auf das 9. Jahrhundert vor Christi datiert. Seit dem 6. Jahrhundert breitete sich die Glockengießerkunst aus Asien aus und gelangte vor dem 8. Jahrhundert nach Europa. Die Verwendung der Glocke bei magischen und kultischen Ritualen war und ist weiterhin weit verbreitet. - Der Große Brockhaus 1983, s. v. Glocke).

Cistov bezeichnet den Verlauf eines nordrussischen Hochzeitstages als kreisförmig: "Der Bräutigam und seine Gesellschaft beschreiten am Hochzeitstag sozusagen einen Kreis: aus seinem Haus in das Haus der Braut, dann in die Kirche, und schließlich kehren sie mit der Braut heim." (Čistov 1981, S. 130).

Auch der Verlauf einer mordwinischen Hochzeit nimmt gewissermaßen eine Kreisform an, obgleich die Braut neben diesem Kreis einen zweiten entstehen läßt, indem sie die Verwandten in ihren Häusern aufsucht und bei ihrem Onkel Unterschlupf sucht, sobald der Bräutigam mit seinem Geleit in ihrem Heim angekommen ist.

Die Hochzeitszeremonien der Türkvölker sind symmetrische Hochzeiten mit zwei Kreisen. Bei der kasan- und auch mischärtatarischen Hochzeit sind die Kreise zeitlich gegeneinander verschoben: Zuerst findet der Teil der Zeremonie statt, wo im Elternhaus und bei der Verwandtschaft der Braut gefeiert wird, darauf wird später im Haus und bei 
den Verwandten des Bräutigams gefeiert; außerdem bilden beide Kreise einen Doppelkreis, da die Feiern der Männer von denen der Frauen getrennt stattfinden.

Im großen und ganzen ähnelt die mischärtatarische Hochzeitszeremonie sehr der türkischen bzw. kasantatarischen Zeremonie. Die Mischärtataren waren Anhänger des Islams und hielten deshalb Mischehen mit nichtgläubigen Russen, Mordwinen oder Tschuwaschen für unpassend (Muchamedova 1972, S. 154. Die Tschuwaschen gehören der orthodoxen Kirche an.). Der Islam hat natürlich auf die Entwicklung der mischärtatarischen und kasantatarischen Hochzeitszeremonie eingewirkt, aber trotz des Eheverbotes kann man in beschränktem Maße fremde Einflüsse annehmen. Laut Muchamedova hat die mischärtatarische Kultur ihre individuellen Züge, die sie von der kasantatarischen Kultur unterscheiden, gerade durch den fortwährenden Kontakt erworben, die die Mischärtataren zu ihren beiden Nachbarvölkern, den Mordwinen und den Russen, aufrechterhielten (Muchamedova a. a. O. S. 17, 225, 226-).

Bei einer tschuwaschischen Hochzeit entstehen die Kreise der Hochzeit der Braut und der Hochzeit des Bräutigams gleichzeitig: Der Bräutigam besucht mit seinen Begleitern die Häuser seiner Verwandten, die Braut gleichzeitig die der ihrigen. Keiner der beiden Kreisläufe wird unmittelbar zu Ende gebracht: Der Bräutigam kommt mit seinen Leuten im Haus der Braut an, die Braut bei ihrem Onkel. Danach vereinigen sich die Kreise aber zu einer Kreisform. Im ganzen hat die Figur viel Gemeinsames mit der der mordwinischen Hochzeit.

Der große Zusammenhang des virilokalen Ritus und der Klagelieder verbindet die tschuwaschische, mischärtatarische, mordwinische und russische Hochzeitszeremonie. Aber in diesem Gesamtbild lassen sich, entstanden durch gemeinsame Züge, zwei Detailgruppen schärfer erkennen. Die tschuwaschischen und mordwinischen Hochzeitszeremonien weisen viele Gemeinsamkeiten auf. Teilweise findet man die gleichen Details auch bei den Mischärtataren vor. In jenen Fällen handelt es sich meist um weiter verbreitete türkische Züge. Aber es gibt darüber hinaus Einzelheiten, die nur bei dem tschuwaschischen und mordwinischen Zeremoniell vorkommen. Ein Detailbild, ein schwächeres, ent- 
steht ferner durch die Merkmale, die die russische Zeremonie mit anderen, besonders der mischärtatarischen oder der mordwinischen gemeinsam aufweist.

Allein schon der gleiche Ausgangspunkt verbindet die tschuwaschische, mischärtatarische und mordwinische Hochzeitszeremonie: Es ist die gleiche Art, zu einer Braut zu kommen. Sowohl bei den Mordwinen als auch bei den Tschuwaschen und Mischärtataren gab es früher (z. B. bei den Mordwinen noch Anfang dieses Jahrhunderts) zwei Möglichkeiten, sich eine Frau zuzulegen: Man kaufte sie, was eine Brautwerbung und Hochzeitszeremonie implizierte, oder man raubte sie (Hämäläinen 1913, S. 23-; Prokop'ev 1903, S. 3; Muchamedova 1972, S. 154). Es war eine allgemeingültige Regel bei den Türkvölkern, daß der Mann seine Frau aus der väterlichen Verwandtschaft erst nach sieben Generationen ohne gemeinsame Vorfahren wählen konnte (Muchamedova 1972, S. 180); die gleiche Vorstellung scheint der mordwinischen Forderung zugrundezuliegen, die Verwandtschaft der Braut müsse bis zu sieben vorhergehenden Generationen bekannt sein (UPTMN 6:1, S. 28). Der unter den Völkern der mittleren Wolga bekannte Brauch, minderjährige Jungen mit erwachsenen Frauen zu verheiraten, ist besonders bei den Mordwinen und Tschuwaschen verbreitet gewesen (Hämäläinen 1913, S. 31-, 105, 146-, 205-; Muchamedova 1972, S. 156), aber er war auch bei den Mischärtataren (Muchamedova 1972, S. 226) und sogar bei den Russen des mittleren WolgaGebietes bekannt (a. a. O. S. 156).

Die Tatsache, daß der Bräutigam zu Beginn der Hochzeitszeremonie unsichtbar bleibt, was bei den mordwinischen Hochzeiten vieler Regionen vorkommt, ist ein typisch türkischer, nämlich uxorlokaler Zug. Der kirgisische Bräutigam darf sich in der Zeit zwischen der Verlobung und der Hochzeit nicht seinen Schwiegereltern oder anderen älteren Verwandten der Braut zeigen. Wenn der turkmenische oder kasachische Bräutigam während der 3. Phase das Recht hatte, seine Frau zu besuchen, mußte er es während der Nacht tun, so daß ihn keiner sah. Der Erklärung der Kasachen zufolge war es eine große Schande, wenn sich der Bräutigam und die Schwiegereltern während der Zeit zwischen der Verlobung und der endgültigen Hochzeit sahen oder trafen (Džumagulov 1960, S. 37). 
Das empfindliche Verhältnis zwischen dem Bräutigam und der Verwandtschaft der Braut erklärt sich wahrscheinlich durch den uxorlokalen Brauch, der sich hinter dem uxorlokalen Ritus vermuten läßt: Der Bräutigam ist im Begriff, in das Gebiet der Sippe der Braut einzudringen. Hämäläinen bringt auch viele Beispiele für die Passivität des Bräutigams bei den Türkvölkern, was die Brautwerbung und die Hochzeitszeremonie anbelangt, und über den Zwang, die Schwiegereltern und die Verwandtschaft der Braut zu vermeiden (Hämäläinen 1913, S. 208-); dieses Verhalten war auch für den tscheremissischen und wotjakischen Bräutigam typisch (ebd.); die Hochzeitszeremonien dieser Völker wie ihre Kultur allgemein weisen viele türkische Züge auf.

Hämäläinen hat ähnliche Verhaltensregeln auch beim wogulischen und ostjakischen Bräutigam verzeichnet (ebd.), aber für diese Völker braucht man nicht von einem türkischen Einfluß auszugehen: Sibirien ist ja das Gebiet der uxorlokalen Eheschließung par excellence (vgl. z. B. Janhunen 1988, S. 282). Daß der mordwinische Bräutigam die Schwiegereltern vermeidet, hat hingegen einen eindeutig türkischen Hintergrund. Seine Abwesenheit bei der Brautwerbung, die dazu führt, daß ein Brautwerber angestellt werden muß, ist jedoch nicht nur für die Türkvölker, sondern auch für viele andere Kulturkreise typisch, und erklärt sich dadurch, daß man sich bemüht, ein neutrales Gebiet, ein Niemandsland, zwischen den Interessengebieten der zwei Sippen zu schaffen.

Bei allen fünf oben dargestellten Hochzeitszeremonien werden zu Beginn der Vorbereitungen verschiedene Personen, sozusagen Rollenträger, mit unterschiedlichen Aufgaben beauftragt, damit sie sowohl der Braut als auch dem Bräutigam zur Seite stehen. (Dieser allgemeingültige Zug ist bei den vorhergehenden Beschreibungen vernachlässigt worden.) Im Mordwinischen, Tschuwaschischen und Mischärtatarischen gibt es einige gemeinsame Termini. Die Mitglieder der Gesellschaft des mordwinischen Bräutigams heißen kuda, das tatarische Wort koda bedeutet soviel wie 'der Vater des Bräutigams' oder 'die Verwandten im Verhältnis zu den Eltern und Verwandten der Braut'. Der Zeremonienmeister des Bräutigams nennt sich bei der ersanischen Hochzeit pokš$k u d a$, 'großer Kuda', bei der mokschanischen Hochzeit oć-kuda ebenfalls 'großer $K u d a$ ', im Tschuwaschischen $p u s ́-\chi \partial D a$ 'Haupt- $\chi$.'; bei der mischärtatarischen Hochzeit ist baš koda 'Haupt-koda' auch 'der Braut- 
werber'. Das mordwinische Wort kuda ist eine Entlehnung aus den Türksprachen. Auch bei den anderen Termini ist die Richtung des Entlehnungsprozesses die gleiche. Der á́ći der mokschanischen Hochzeit ist 'der Bruder oder ein anderer naher männlicher Verwandter im Festzug der Braut'; im Mischärtatarischen hat das Wort арчи häufig die Bedeutung 'Überbringen der Braut in das Haus des Bräutigams' (z. B. Tatary srednego Povolž'ja i Priural'ja, S. 247), im Tatarischen bedeutet das Wort 'der Begleiter der Braut' (das Wort hat Entsprechungen in anderen Türk- und Mongolsprachen; s. Achmet'janov 1981, S. 76-). Der türkische Begriff $t u j$, 'die Hochzeit', ist ebenfalls ins Mordwinische entlehnt worden, hat jedoch eine Bedeutungsverschiebung zu 'Lösegeld für die Braut' erfahren.

Einen typischen türkischen Zug bei der mordwinischen Hochzeit stellt dar, daß die Braut in vielen Gebieten in einem gedeckten Wagen in das Haus des Bräutigams transportiert wird. Laut Muchamedova handelt es sich bei diesem Brauch um einen Überrest aus der uxorlokalen Phase: Noch vor kurzem war es bei den meisten Türkvölkern Sitte, dem Bräutigam einen eigenen gedeckten Wagen oder eine Jurte zur Verfügung zu stellen, sobald er das Lösegeld gezahlt und in das Haus der Braut gekommen war. Es war derselbe gedeckte Wagen, in dem das Ehepaar dann in das Dorf des Bräutigams fuhr (Muchamedova 1972, S. 168). Schon der Name des gedeckten Wagens, der bei einer mordwinischen Hochzeit verwendet wird, ist türkischen Ursprungs (onava, vgl. nogaisch omayü). Im Mordwinischen ist sogar die ursprüngliche Funktion des gedeckten Wagens in der dialektalen Bezeichnung ul'emakudo 'die Hütte, in der man sich aufhält', erhalten geblieben (Evsev'ev 1966, S. 277)!

Beim Empfang der Braut im Haus des Bräutigams spielt der Herd bzw. der Ofen sowohl bei den Türkvölkern als auch bei den Mordwinen eine große Rolle. Das ist die Stelle, wohin die Braut als erstes gebracht wird. Die mischärtatarische Braut mußte den Ofen sogar küssen (Muchamedova 1972, S. 171). Bei der virjal-tschuwaschischen Hochzeit bricht die Braut beim Verlassen des Elternhauses Lehm vom Ofen und sagt: "Komm mit mir, Schutzgeist des Hauses!" (Magnickij 1881, S. 205). (Die Mokschamordwinen nahmen beim Umzug in ein neues Haus Feuer und Asche aus dem alten Heim mit, da man annahm, der 
Schutzgeist des Hauses sei an das Haus und vor allem an den Herd gebunden, berichtet Harva, indem er sich auf eine ältere Quelle beruft Harva 1942, S. 178.) Überall in Zentralasien haben die türkischen und mongolischen Bräute bei der Ankunft im Haus des Bräutigams auf dem Herd, in das Feuer opfern müssen (Harva 1933, S. 159-). Einen eigentlichen Schutzgeist scheint der Herd für diese Völker nicht repräsentiert zu haben; er ist die "deutlichste Verbindung zwischen den Mitgliedern der Sippe" gewesen, mit dem man die Mutter Feuer anbetete. Die Verbindung zwischen dem heimischen Feuer und dem Zusammenhalt der Familie wird dadurch verdeutlicht, daß fremde Personen nicht an dem Feuerkult einer Familie in ihrem Heim teilnehmen konnten (a.a. O. S. 158).

Der Türrahmen besitzt eine Funktion sowohl bei der mordwinischen als auch bei der türkischen Hochzeit. Sowohl die mordwinische als auch die Braut eines Türkvolkes - und zwar sowohl die, die in mehreren Phasen der Hochzeitszeremonie Brautklagen vorträgt, d. h. die tschuwaschische und mischärtatarische Braut, als auch die, die lediglich eine Abschiedsklage für die Anverwandten vorträgt - klammert sich an den Türrahmen, sobald sie aus dem Elternhaus getragen wird, um in das Haus des Bräutigams gebracht zu werden. Diese türkischen Bräute, die Brautklagen anstimmen, sind Bräute im virilokalen Ritus, und eben die Art und Weise, in der die Braut aus dem einen in das andere Haus geschafft wird, unterscheidet sich grundlegend beim virilokalen und uxorlokalen Ritus: Es scheint für den virilokalen Ritus typisch zu sein, daß der Bräutigam oder zumindest Leute aus seinem Festzug kommen, um die Braut aus dem elterlichen Haus in das Haus seiner Eltern zu holen; bei dem uxorlokalen Ritus wird die Braut von ihren eigenen Verwandten in die Nähe des Hauses des Bräutigams oder in die dort eigens für diesen Zweck aufgestellte Jurte gebracht, d. h. auch hier findet der Wechsel aus der Domäne der einen Sippe in die der anderen schrittweise statt. Im virilokalen Ritus wird die Braut sozusagen aus ihrem heimischen Umfeld herausgerissen; um ihren oft aufrichtigen Widerwillen kundzutun, klammert sie sich noch an den Türrahmen.

Ein weiterer Zug, den die tschuwaschische und die mischärtatarische Zeremonie mit der mordwinischen gemeinsam hat, ist das Beschenken der Braut durch ihre zukünftige Schwiegermutter bei der Gelegenheit, wo das Lösegeld für die Braut entrichtet wird. Die mi- 
schärtatarische Schwiegermutter gibt der Braut einen Ring in einem Bierglas; die zukünftige mordwinische Schwiegermutter schenkt ihr auch anderen Schmuck. Deshalb ist die mordwinische Braut denn auch nach der Beschenkung "der markierte Baum" ihrer Schwiegermutter. Bei derselben Gelegenheit hat die tschuwaschische Schwiegermutter ein Säckchen Schmuckgeld und ein paar Rubel für den Kopfputz der verheirateten Braut mitgebracht, der noch für die Braut angefertigt werden soll (Paasonen 1949, S. 3-); auch hier handelt es sich eindeutig um ein "Vormerken" der Braut. Das "Vormerken der Braut" fand zwar früher auch in der russischen Zeremonie statt, geschah aber auf ganz andere Art und Weise. Der Älteste der Gesellschaft des Bräutigams setzte ihr seine Fellmütze auf; dies war ein otmetka nevesty (Mahler 1960, S. 324-). Ich habe hier nicht klären können, ob der Brauch einen gemeintürkischen Hintergrund hat oder ob er vom Ursprung her eher russisch ist.

Neben den Charakteristika, die der mordwinischen, tschuwaschischen, mischärtatarischen und gemeintürkischen Hochzeit gemeinsam sind, gibt es auch Merkmale, die lediglich bei der tschuwaschischen und mordwinischen Hochzeit vorkommen.

Hierher gehört beispielsweise, daß sich die Braut im Haus des Onkels versteckt, wenn der Bräutigam mit seinen Leuten kommt, um sie zu holen, und der Statuswechsel von einem Mädchen zu einer Ehefrau im Heim des Onkels geschieht. Auch der Brauch, die Braut außerhalb der Dorfgrenze der Gesellschaft des Bräutigams zu übergeben, ist ein solcher Zug. Als kleine Gemeinsamkeit sei an die Klagelieder erinnert, die die Braut den Pferden singt, die sie gezogen haben.

Darüber hinaus besitzen beide Bräute die bemerkenswerte Gemeinsamkeit, daß sie bzw. eine Schwägerin oder Schwester an ihrer Stelle unmittelbar vor dem Verlassen ihres Elternhauses Geschenke an ihre eigenen Verwandten verteilen; bei anderen Hochzeitszeremonien, z. B. bei der russischen, verteilen die Bräute Geschenke lediglich an die Verwandtschaft des Bräutigams. Balys hält die letztere Variante für einen bei den Indogermanen weit verbreiteten Brauch, der "das Sicheinkaufen der Braut durch Geschenke in die Gemeinschaft des Mannes" als Funktion habe (Balys 1946, S. 58.) 
Aber auch die mordwinische und tschuwaschische Brautklage besitzen gemeinsame Züge, z. B. das Übereinstimmen der Terminologie ist äußerst interessant. Es gibt zwei Bezeichnungen für die mordwinische Brautklage. Eine ist ersanisch avaŕkšñema, mokschanisch avaŕkšñama, denen das Verb 'weinen' zugrunde liegt, das andere ist ersanisch urńema bzw. mokschanisch urńama, denen ein Verb mit der Bedeutung 'heulen, lauthals weinen' zugrunde liegt; durch sie werden die Klagen der Braut am Abend oder während der Nacht bezeichnet. Mit diesen Klagen nimmt die Braut Kontakt zu den Ahnen auf, wobei sie die Melodie einer Totenklage übernimmt (Vdovin 1972, S. 362). Die tschuwaschische Brautklage hat ebenfalls zwei verschiedene Benennungen.

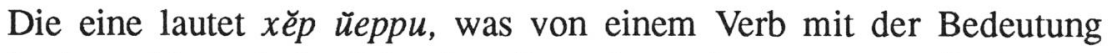
'weinen, klagen' abgeleitet ist, die andere $x \breve{p}$ хйхxu, wo die Bedeutung der Wurzel 'kreischen, jammern' ist, oder хёр хӥхлеве, wo die Wurzel '(wie ein Schakal) heulen' ist. Letztere Benennungen werden auch ohne den Vorsatz xёp 'Mädchen-' von der Totenklage verwendet.

Es ist leider nicht möglich, aus den Quellen zu ersehen, ob es Unter-

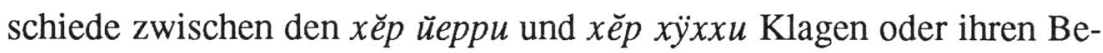
legkontexten gibt. Genauso wenig ist es möglich zu erfahren, ob es tschuwaschische Kontaktklagen gibt, d.h. Klagen, mit denen man Kontakt aufnimmt zu den unterirdischen, verstorbenen Verwandten. Paasonen weiß zwar, daß die tschuwaschische Braut mit ihren Ahnen sprechen geht, aber sie stimmt zu diesem Zweck keine Brautklage an, sondern spricht ein Gebet.

Die Art und Weise, wie eine tschuwaschische Braut ihr Klagen beginnt, ähnelt den Berichten über das Verhalten der mokschanischen Braut von Evsev'ev und Paasonen sehr. Die tschuwaschische Braut befindet sich am Morgen des Hochzeitstages im Speicher. Sie ist in ihr Hochzeitsgewand gekleidet und trägt einen weißen Überwurf. Eine verheiratete Schwester und Schwägerin von ihr reichen ihr abwechselnd Bier in einer Zaumzeugglocke und sagen zu ihr: "Möge sie ihre Klagen vortragen mit einer Stimme, die ebenso hell ist wie das Geläut dieser Glocke!". Beide Frauen, d.h. die Schwester und die Schwägerin, setzen sich neben die Braut, bedecken auch ihre eigenen Häupter mit demselben Überwurf und stimmen ein Klagelied an. Nach der Einführungsklage schütteln die Frauen den Überwurf $a b$, und die Braut klagt allein 
unter der Decke weiter (Paasonen 1949, S. 26-). Auch die mokschanische Braut, mancherorts auch die ersanische, hat eine Schwägerin bei sich, die ihr hilft, die Klagelieder anzustimmen. Paasonen schildert, wie sie am Hochzeitstag nebeneinander im Wohnraum sitzen, beide mit bedeckten Häuptern, und die Schwägerin anfängt: "Vorfahren! Gebt eine Stimme, die der Glocke von Moskau gleicht; gebt Worte, die wie verlesene Erbsen sind!" Danach fährt die Braut allein fort, unter ihrer Verschleierung zu klagen (Paasonen 1947, S. 513-). Evsev'ev hat ähnliches verzeichnet (1966, S. 431-) und ein entsprechender Tatbestand ist fast achtzig Jahre später festgehalten worden (UPTMN 6:2, S. 62-).

Wie erwähnt gibt es auch Charakteristika, die der russischen und der mischärtatarischen oder der mordwinischen Hochzeit oder allen dreien gemeinsam sind. Solche sind "der Mädchenabend" vor der Hochzeit und oft das damit verbundene symbolische Weggeben des Mädchentums oder das Betrachten des Hauses, des Haushalts des Bräutigams seitens der Familie der Braut sowie die Bestätigung der Verlobung durch den Handschlag der Schwiegerväter oder ferner, daß der mischärtatarische Bräutigam die Möglichkeit hat, die Braut vor der Hochzeit in ihrem Zuhause zu besuchen. Diese sind Züge, die man wegen ihres teils symbolischen Inhalts als spätere Triebe im Wachstum der Hochzeitszeremonie bezeichnen möchte - mit Ausnahme des letzterwähnten Zugs, der von dem Sieg des virilokalen Ritus gegenüber dem uxorlokalen zeugt. Sie greifen nicht so tief in die Basis der Zeremonie wie die Gemeinsamkeiten, die die Zeremonie der Türkvölker, besonders der Tschuwaschen, und der Mordwinen verbinden. Wie sind diese tiefgreifenden Gemeinsamkeiten entstanden?

Auch für die Betrachtung der Klagehochzeit relevante Fragen sind, wann die Mordwinen Teil der türkischen Kulturzone geworden sind, wie diese Kultur beschaffen war und wann die Mordwinen speziell mit den Tschuwaschen und Mischärtataren in Berührung gekommen sind.

Paasonen hat angenommen, im mittleren Wolga-Gebiet habe schon vor der mongolisch-tatarischen Eroberung im 13. Jahrhundert ein Türkvolk gelebt, dessen Sprache nicht bolgarisch war (Paasonen 1903, S. 49-). Er vermutet, daß die Sprache der Karatajmordwinen, die im 17. Jahrhundert noch Mordwinisch sprachen, seitdem aber tatarisch geworden sind, Spuren einer solchen Sprache in ihrer eigenen konserviert 
haben. Außerdem erwägt er den möglichen Einfluß der Burtaschen im Wandlungsprozeß. Chalikov möchte alle nomadischen oder halbnomadischen Züge der archäologisch belegten Kulturen des Wolga-KamaUral-Gebietes aus dem 4.-6. Jahrhundert mit Türkstämmen in Verbindung gebracht sehen. Zimonyi hält diese Behauptung jedoch für $\mathrm{zu}$ kühn: Man könne nicht ausschließen, daß türkische Stämme schon im 3.-6. Jahrhundert in das Wolga-Kama-Gebiet eingedrungen seien, aber es sei nicht möglich, den rein türkischen Ursprung der nomadischen Merkmale der Funde zu beweisen (Zimonyi 1990, S. 52-, 57).

Als die Vorfahren der Tschuwaschen, die Wolgabolgaren, Ende des 8. Jahrhunderts in die Gegend um das Wolgaknie kamen, waren sie Nomaden. Noch Anfang des 10. Jahrhunderts, als ihr Staat seine Blütephase erlebte, waren sie trotz ihrer weit entwickelten Agrarkultur weiterhin Nomaden (Zimonyi 1990, S. 176). Ihr Hauptsiedlungsgebiet lag am linken Ufer der Wolga. Was ihre vormongolischen Siedlungsgebiete rechts der Wolga betrifft, scheinen sie sich um den Fluß Svijaga und in den Tälern der kleineren Nebenflüsse auf der rechten Seite der Wolga konzentriert zu haben (Bereczki 1979, S. 10). Aus der archäologischen Karte in Zimonyis Werk wird ersichtlich, daß sich die frühen Siedlungsgebiete der Bolgaren sporadisch bis westlich der Svijaga ausgedehnt haben (Zimonyi 1990, S. 185).

Die Mordwinen waren zumindest locker in den Machtbereich der Wolga-Bolgaren eingegliedert (Kappeler 1982, S. 24-), und es wird angenommen, daß unter den finnisch-ugrischen Bevölkerungsteilen, die seither von den Tschuwaschen absorbiert worden sind, auch mordwinische Gruppierungen waren (Denisov - Ivanov 1985, S. 177, vgl. auch Kappeler 1982, S. 31). Die Eroberung durch die Mongolen bescherte den Mordwinen ein ähnliches Schicksal wie den Bolgaren (Kappeler 1982, S. 31). Im Machtbereich der Goldenen Horde standen die Mordwinen zwischen zwei Fronten: Sowohl die tatarischen als auch die russischen Truppen verwüsteten ihr Gebiet, und teilweise wurden sie tatarischen oder russischen Fürsten unterworfen (a.a. O. S. 38). Kappeler zufolge gehörten zum Khanat Kasan beträchtliche Gruppen von Mordwinen (a.a.O. S. 44). Außerdem habe der Khan jene mordwinischen Untertanen, die später als Karatajmordwinen bekannt wurden, in das Zentrum seines Reiches umsiedeln lassen (a.a. O. S. 61; vgl. Paaso- 
nen 1903, S. 49-). Im 16. Jahrhundert waren der Unterlauf der Sura, ihr linker Nebenfluß Alatyr und der Oberlauf der Mokscha Grenzflüsse zwischen dem Khanat und dem Großfürstentum Moskau (Kappeler 1982, S. 42; Kappeler 1992, Karte S. 27). Daraus folgt, daß Mordwinen schon vor Mitte des 16. Jahrhunderts auf dem Gebiet des Khanats, nämlich südlich der Mündung des Alatyr auch östlich der Sura gelebt haben müssen. ${ }^{1}$

Einer älteren Auffassung zufolge hätten keine Mordwinen vor dem Zusammenbruch des Khanats östlich der Sura gelebt (Paasonen 1897, S. 9; 1903, S. 41). Die große Wanderung der Mordwinen ostwärts über die Sura hat allerdings erst nach dem Untergang des Khanats begonnen, d.h. nach der Mitte des 16. Jahrhunderts (Paasonen 1897, S. 9). (Die Mischärtataren des Kadomgebietes sind, offensichtlich wegen der Maßnahmen der Regierung Iwan des Schrecklichen, etwa zur gleichen Zeit ebenfalls nach Osten aufgebrochen - Szíj 1990, S. 274: eine Tabelle aus dem Manuskript von A. Berta.)

Die Sura scheint nie eine Barriere für die Übernahme von kulturellen Erscheinungen dargestellt zu haben. Schon die Ostgrenze jener Gorodec-Kultur der frühen Eisenzeit, als deren Träger man die Mordwinen vermutet hat, verlief nicht die Sura entlang, sondern hinter der Wolga (Szíj 1990, S. 134: eine Karte aus dem Werk Eesti ajalugu). Die Grenze der Textilkeramikkultur der Bronzezeit, die auf demselben Gebiet der Gorodec-Kultur vorausging, machte einen ähnlichen Bogen hinter die Wolga (Szíj a. a. O. S. 129-130; die Karte basiert auf Huurre und wird von Carpelan präsentiert); ebenso die Grenze der Balanovo-Kultur, die zumindest von Gimbutas als ursprünglich baltisch eingestuft wird (Gimbutas 1983, S. 63, 67, 77).

Nachdem die mongolisch-tatarischen Eroberer im 13. Jahrhundert den Staat der Bolgaren verwüstet hatten, wurden die Bolgaren am linken Wolgaufer tatarisch. Die Bolgaren am rechten Ufer bewahrten ihre Sprache. Nach Meinung des ungarichen Forschers Róna-Tas entstand aus den Bolgarengruppen, die vor den mongolischen Eroberern geflohen und den sich ausbreitenden Tataren gewichen waren, während des 13. und 14. Jahrhunderts das Volk der Tschuwaschen.

Die ursprünglichen Bewohner des Gebietes, die finnisch-ugrisch waren, beeinflußten die Entstehung der neuen Nation entscheidend. 
Schon im 10. Jahrhundert hatten die Bolgaren ständige Kontakte zu den Permiern unterhalten, und im 13. Jahrhundert kamen sie in engen Kontakt zu anderen finnisch-ugrischen Völkern, indem sie vor den Tataren zurückwichen. Der Kontakt war derart eng, daß es zur Assimilation kam: "The Chuvash have assimilated Finno-Ugrian ethnic groups to a significant extent" schreibt Bereczki (Vikár - Bereczki 1979, S. 78).

Das nördliche Siedlungsgebiet der Virjaltschuwaschen erweist sich schon durch die Toponymie als altes Tscheremissen-Gebiet (Bereczki a. a. O. S. 78); ein Teil der tscheremissischen Bevölkerung ging in den bereits 1230-1250 eingedrungenen Bolgaren auf (Bereczki a. a. O. S. 11). Der andere Teil der Tscheremissen wich nach Norden und nach Nordosten aus (ebd.). Auch eine mordwinische Komponente ist für die tschuwaschische Ethnogenese vermutet worden (Denisov - Ivanov 1985, S. 177). Der Süden der jetzigen Tschuwaschenrepublik verödete schon im 14. und 15. Jahrhundert, nachdem es durch die Verwüstungszüge verschiedener Nomadenstämme unbewohnt geworden war. Die Bolgaren, die Ackerbauern waren, hatten sich in die Waldgebiete zwischen den Flüssen Civil' und Svijaga gerettet. Erst im 17. Jahrhundert machten die Tschuwaschen den südlichen Teil der Republik wieder schrittweise urbar (Bereczki 1979, S. 13; Denisov - Ivanov 1985, S. 177).

Róna-Tas nimmt an, daß die Dialektgrenze zwischen der nördlichen Virjalgruppe und der südlichen Anatrigruppe erst nach dem Untergang des Khanats von Kasan enstanden ist (Róna-Tas 1982, S. 126. Vgl. Róna-Tas 1978, S. 35). Der Unterschied zwischen den beiden Gruppen habe sich dadurch verstärkt, daß die Virjalgruppe jahrhundertelang Kontakte zu den Bergtscheremissen und auch zu den Russen aufrechterhalten hätte, während die Anatrigruppe wieder Beziehungen zu den Kasantataren hätte. Dies macht sich sowohl in der Sprache (Róna-Tas 1978, S. 80-) als auch in der Kultur, z. B. in der Musik (Vikár in Vikár - Bereczki 1979, S. 32, 37-), und in der Kleidung der Frau (Lehtinen 1979, S. 137) bemerkbar. Nach dem Untergang des Khanats von Kasan begann die Unterwerfung der Tschuwaschen unter die Macht von Moskau und ihre Bekehrung zur orthodoxen Kirche. Es scheint, als hätten sich nicht alle Gruppen im Bolgarenstaat des 10. Jahrhunderts zum Islam bekannt (Bereczki 1979, S. 11). 
Die tschuwaschischen Forscher vertreten eine ganz andere Auffassung über die Ethnogenese der Tschuwaschen. Denisov und Ivanov zufolge hat die Assimilation der alten Einwohner des rechten Wolgaufers, der finnisch-ugrischen Tscheremissen, der Burtaschen und teilweise auch der Mordwinen, sowie der Neuankömmlinge, der türkischen Bolgaren, bereits im 9. und 10. Jahrhundert begonnen, was zur Entstehung der Virjaltschuwaschen, die heute die nördliche Gruppe der Tschuwaschen ausmachen, geführt hätte. Südlich von ihnen seien im 13. Jahrhundert, d.h. nach den Eroberungszügen der Mongolen, die mit den Bolgaren engverwandten Suwaren eingedrungen, aus denen die südliche Gruppe der Anatritschuwaschen hervorgegangen sei (Denisov - Ivanov 1985, S. 177).

Das Gebiet der Tschuwaschen liegt östlich der Sura, das der Mordwinen südwestlich von ihr. Die späteren Tschuwaschen und die Mordwinen haben Kontakte nur in einigen kleinen Gebieten gehabt, in den Gouvernements Kasan und Simbirsk (Paasonen 1897, S. 8). In der Zeit vor dem Mongolensturm müssen weiträumigere Kontakte bestanden haben - von ihnen zeugen auch die - allerdings nur wenigen - bolgarischen Lehnwörter im Mordwinischen (Paasonen a. a. O. S. 7), und es hat also auch die Möglichkeit zu Kontakten gegeben, wie die Geschichtsforschung gezeigt hat. Oben wurde auch darauf hingewiesen, daß die Sura nie eine Grenze für die Verbreitung von Kulturerscheinungen gebildet hat.

Viele wichtige Details verbinden die tschuwaschische und mordwinische Hochzeitszeremonie und nur diese beiden Zeremonien. Wie bereits erwähnt wurde, sind solche Einzelheiten das zeitweilige Unterbringen der Braut im Hause ihres Onkels, und daß ihr dort die Symbole der Ehefrau überreicht werden, die Übergabe der Braut außerhalb der eigenen Dorfgrenzen, die Geschenke und der Segen, den die Braut vor ihrem Aufbruch aus dem Elternhaus ihren Angehörigen und dem Zuhause spendet, und ihre Hinwendung zu den Ahnen in entscheidenden Situationen.

Hinter diesen Einzelheiten scheint sich ein Plan zu verbergen. Die Braut wird aus dem Kreis ihrer Verwandtschaft, aus ihrem Heim behutsam übergeben. Der Abschied wird dadurch gemildert, daß die Braut 
ihre Verwandtschaft beschenkt (die mordwinische Braut beschenkt sogar ihre Vorfahren), und das gefährliche Unternehmen der Auslieferung wird verharmlost, indem die Braut erst von ihrem eigenen Haus zu ihrem Onkel, dann vom eigenen Hof bis hinter die Dorfgrenze gebracht wird. Die Klagelieder, mit denen die Braut ihr Verhältnis zu Ahnen und Verwandtschaft klärt, passen natürlich auch ins Bild.

Ein solcher Plan wäre in einer großen Umbruchsituation notwendig gewesen, und zwar beim Übergang von der uxorlokalen, einschließlich der vorübergehend uxorlokalen, Eheform zur virilokalen. Daß der uxorlokale Ritus bei den Tschuwaschen erst relativ kurze Zeit zurückliegt, verdeutlicht sich im Ritus selbst dadurch, daß der Bräutigam in der Anfangsphase der Hochzeit lange abwesend ist und daß die Braut im Niemandsland außerhalb der Grenzen ihres Heimatdorfes den Leuten des Bräutigams übergeben wird. Dabei scheint dies eine Kompromißlösung zwischen uxorlokalem und virilokalem Ritus zu sein: Die Braut wird weder gemäß dem uxorlokalen Ritus bis auf das Gebiet der Verwandtschaft des Bräutigams zur Übergabe gebracht noch wird sie wie die Braut eines virilokalen Ritus in ihrem eigenen Heim übergeben. Der Umbruch muß den Türkvölkern, die als Nomaden und Halbnomaden in das Ackerbaugebiet der mittleren Wolga kamen, abrupt erschienen sein.

Der Wechsel des Erwerbszweiges verursacht an sich noch keine Veränderungen in der Eheform und im Hochzeitsritus; auch die Kasantataren sind Ackerbauern geworden, doch haben sie die vorübergehende uxorlokale Ehe und den uxorlokalen Ritus beibehalten. Der wirtschaftliche Strukturwandel ist also eher die Voraussetzung als die Ursache des Wandels im Ritus - entsprechend ist der virilokale Ritus Voraussetzung für die Entstehung der Klagehochzeit, aber keineswegs ihre Ursache.

Es ist möglich, daß einige der Gemeinsamkeiten der tschuwaschischen und mordwinischen Hochzeitszeremonie im kulturellen Wirkungskreis der Bolgaren entstanden sind. Schließlich haben die Mordwinen auch Eigenheiten aus anderen Bereichen der Kultur von den Bolgaren entlehnt. Sie haben z. B. die Verehrung des Keremet, und zwar sogar des Soltan-keremet, übernommen (Harva 1942, S. 198-). Ebenfalls bolgarischen Ursprungs dürfte der heilige Ort, der "reine Ort", des Hauses sein, der für den Ahnenkult der Mordwinen von größter Bedeutung ist (Literaturhinweise z. B. bei Bartens 1990, S. 112). (Bei den Tschere- 
missen und Wotjaken ist wahrscheinlich die mit dem Ahnenkult zusammenhängende "Stelle, an die man die Rinde wirft" ebenfalls auf bolgarischen Einfluß zurückzuführen, wie Harva vermutet hat). Diese kulturellen Erscheinungen sind sowohl bei den Ersanen als auch bei den Mokschanen bekannt.

Im Gegensatz zu den oben genannten Erscheinungen kann das Auftreten eines Stellvertreters des Toten, das uns aus dem tschuwaschischen und mordwinischen Kultus für einen Verstorbenen bekannt ist, bei den Tschuwaschen finnisch-ugrischen Ursprungs sein (Literaturhinweise s. Bartens 1990, S. 121).

Die übergreifende Strukturierung der tschuwaschischen und der mordwinischen Hochzeitszeremonie kann ebenfalls nicht als bolgarisch angesehen werden. Wollte man dies tun, wäre es unbegreiflich, warum dieser Ritus nicht auch auf die tscheremissische und wotjakische Zeremonie eingewirkt hat. Und davon kann bei der Hochzeitszeremonie jener Völker, die sonst so stark durch die bolgarische Kultur geprägt sind, keine Rede sein. Die Gemeinsamkeiten der tschuwaschisch-mordwinischen Hochzeitszeremonie müssen aus dem Zusammenprall genau dieser beiden Kulturen entstanden sein; deshalb zeigt sich die Wirkung auf der tschuwaschischen Seite am deutlichsten bei den Anatritschuwaschen. Östlich der Sura gab es schon früh eine Berührungsfläche für die mordwinisch-tschuwaschischen Kontakte. Als dann nach dem $\mathrm{Zu}$ sammenbruch des Khanats die große Ostwanderung der Mordwinen begann, sind sie möglicherweise auch durch das Siedlungsgebiet der Anatritschuwaschen gezogen. Und da diese Gebiete sogar während der zwei oder drei vorhergehenden Jahrhunderte unbesiedelt waren, da sie zu unsicher waren, kann man sich vorstellen, daß nicht nur die Tschuwaschen, sondern auch die landbauenden Mordwinen herbeieilten, um das fruchtbare Land neu zu bestellen. In dasselbe Gebiet waren ja bereits Mischärtataren gekommen (Muchamedova 1972, S. 19).

Dies wäre also der Nährboden für die Brautklage der Anatritschuwaschen gewesen. Bei einer solchen Hypothese müßte man annehmen, daß die von Magnickij aufgezeichneten Brautklagen der Virjaltschuwaschen aus dem südlichen Anatrigebiet stammten.

Was die Brautklage anbelangt, sind die Tschuwaschen die passive Seite gewesen. Die auffallenden Ähnlichkeiten zwischen der tschuwa- 
schischen und der mordwinischen Hochzeitszeremonie deuten darauf hin, daß auch die Brautklage ein Charakteristikum ist, das eher diese beiden Traditionen in Verbindung zueinander setzt als die tschuwaschische und die russische Tradition. Es ist unmöglich, die urmordwinischen Wurzeln der mordwinischen Brautklage zu bezweifeln. Außer der starken Ähnlichkeit zwischen ersanischer und mokschanischer Klage geben auch die Zeugnisse der Sprache wertvolle Hinweise für die Datierung (Bartens 1990, S. 115-, 1991, S. 46-). Die Hypothese ist also durchaus möglich, daß der Ursprung der ersanischen und mokschanischen Brautklage in der Zeit vor dem Ende des ersten Jahrtausends nach Christi oder spätestens in der Zeit vor der mongolischen Eroberung zu suchen ist. Die Experten der mordwinischen Geschichte lenken unsere Aufmerksamkeit auch auf die frühe Differenzierung der ersanischen und mokschanischen Identität; bekanntlich haben die beiden Volksgruppen kein Hyperonym für sich selbst (vgl. Kreindler 1985, S. 237). Es fanden keine Eheschließungen zwischen ihnen beiden statt (Kreindler a. a. O. mit Quellenverzeichnis. Nur Evsev'ev hat berichtet, nah beieinander siedelnde Gruppen hätten sich eine Braut aus den Reihen des jeweils anderen Volkes geholt - Evsev'ev 1966, S. 321). Es gibt also keinen Grund zu der Annahme, die Gemeinsamkeiten zwischen der ersanischen und mokschanischen Hochzeitszeremonie und der Brautklage ließen sich durch Entlehnung in die eine oder andere Richtung erklären. Wie bei der mischärtatarischen Zeremonie kann es sich bei der tschuwaschischen auch um eine Verankerung der Brautklage handeln: Es ist möglich, daß die Abschiedsklage der Braut schon zur altbolgarischen Kultur gehörte. (Weiterhin kann man sich die Frage stellen, ob nicht die älteste permische Brautklage, die Abschiedsklage der Braut, vgl. Bartens 1991, die tscheremissische und die ungarische Abschiedsklage sowie möglicherweise die Brautklage des bulgarischen Rhodope-Gebietes derselben altbolgarischen Kultur entstammen.)

Das durch die Kultur entstandene Bild einer fruchtbaren Wechselwirkung zwischen Tschuwaschen und Mordwinen spiegelt sich jedoch nicht in der Sprache wider. Im Mordwinischen gibt es nur wenige bolgarische Lehnwörter (Paasonen 1897, S. 5-), und die Zahl der finnischugrischen Lehnwörter im Tschuwaschischen ist noch geringer (Benzing 1959, S. 695-). 
Das Bild, das aus den Bestandteilen des mordwinischen Ritus entsteht, enthält Widersprüche. Bestimmte Ähnlichkeiten mit der tschuwaschischen Hochzeitszeremonie: die Abwesenheit des Bräutigams in den Anfangsphasen der Hochzeit und die Übergabe der Braut an der Dorfgrenze, sind deutlich Charakteristika, die auf die zeitliche Nähe zum uxorlokalen Ritus hinweisen, wie oben konstatiert wurde. Aber das frühe Vorhandensein des mordwinischen Klagelieds deutet wiederum auf das hohe Alter des virilokalen Ritus hin. Die Mordwinen sind ja alteingesessene Bewohner im Zentrum jenes Gebiets, in dem die Brautklage und Klagehochzeit entweder existiert hat oder weiterhin existiert und in dem der Ursprung der Agrargesellschaft bis an den Anfang der Bronzezeit zurückverfolgt werden kann. Das Verhalten des Bräutigams und die Art der Übergabe der Braut werden besonders in den älteren Schilderungen über die mordwinische Hochzeit beschrieben. Diese alten Schilderungen enthalten viele Informationen eben aus östlichen mordwinischen Gebieten, Lepechin z. B. aus dem Gouvernement Simbirsk, Evsev'ev aus dem Gebiet Alatyr, also von östlich der Sura. Es gibt Schilderungen aus anderen Gebieten, wo diese Erscheinungen gar nicht erwähnt werden. Sind sie dort vergessen worden oder hat man sie dort nie gekannt? Hat es auch innerhalb des mordwinischen Gebiets, aber nur hie und da, den Zusammenprall der beiden Riten gegeben? Das würde die Widersprüche in dem Bild, das die mordwinische Tradition bietet, erklären.

Muchamedova vertritt ebenfalls die Meinung, daß die Bolgaren schon früh an das rechte Ufer der Wolga gelangt sind. Sie geht nämlich von zwei türkischen Schichten in der ethnischen Zusammensetzung der Mischärtataren aus: vom vormongolischen bolgarischen Typ des rechten Wolgaufers und von einem nachmongolischen kiptschakischen Typ (Muchamedova 1972, S. 15-).

Das frühe Kerngebiet der Mordwinen befand sich zwischen den Flüssen Oka und Sura. Das zersplitterte Siedlungsgebiet der Mischärtataren erstreckt sich im Westen fast bis zur Oka (in die Gegend von Kerensk, Kadom) und im Osten besonders bei Alatyr bis über die Sura hinaus bis zur Svijaga. Offensichtlich hat zwischen Mordwinen und Mischärtataren seit der Entstehung des mischärtatarischen Volks- 
stammes eine geographische Verbindung bestanden (vgl. Paasonen 1897, S. 8-; Szíj 1990, S. 273, 274). Zur Zeit der Goldenen Horde erstreckte sich das Gebiet der Mischärtataren im Norden bis in die Gegend von Kadom und Temnikov (Muchamedova 1972, S. 18). Die Etablierung des tatarischen Kulturkreises drückte sich noch 1536 in der Gründung großer Zentren, ulus, in Temnikov und dem heutigen Narovčat aus; die Mokschanen standen unter ihrem Einfluß (Balašov Mart'janov 1985, S. 113).

Es ist möglich, daß die Mordwinen nicht nur mit den Mischärtataren in Berührung kamen, sondern auch mit anderen Tatarengruppen. Paasonen vermutete ja einen frühen tatarischen Einfluß im Mordwinischen. Ferner: Die Nogaier bewegten sich zur Zeit der Goldenen Horde auf einem großen Steppengebiet von der Wolga bis zur Dobrudscha (Menges 1959, S. 436). Die Russen errichteten noch 1570/71 am rechten Ufer der Wolga die Grenzbastion Tetjuši, um sich gegen nogaische Angriffe zu schützen (Kappeler 1982, S. 139). Später löste das Eindringen der Kalmücken in die Steppengebiete östlich der Wolga Bewegung unter den Nogaiern westlich des Flusses aus (Kappeler 1992, S. 45).

Ein eventueller Hinweis auf mordwinisch-nogaischen Kontakte kann auch im Rahmen dieser Betrachtung der Hochzeitsbräuche gefunden werden. Die mordwinische Bezeichnung für den gedeckten Wagen, mit dem die Braut transportiert wird, onava, hat möglicherweise in nogaitatarisch omayŭ eine Entsprechung (der entsprechende mischärtatarische Terminus lautet бәдәк мәдәк, der tschuwaschische куме Muchamedova 1972, S. 168). Allerdings scheint die Begegnung mit den Nogaiern eher feindlich verlaufen zu sein, da noch im 17. Jahrhundert jegliche Feinde als "Nogaier" bezeichnet wurden (Spuler 1983, S. 10). Die Bitte der mordwinischen Braut in ihren Klagen, sie vor den Nogaiern, d.h. dem Bräutigam und seinen Leuten zu bewahren, deutet folglich nicht unbedingt darauf hin, daß diese Formeln aus der Zeit der Goldenen Horde stammen (vgl. UPTMN 6:1, S. 13).

Bei den Kontakten zwischen Mordwinen und Mischärtataren waren die Mischärtataren in der Regel der gebende Teil, was sich besonders im tatarischen Lehnwortschatz des Mordwinischen niedergeschlagen hat (Paasonen 1897, S. 8-). Viele der gemeintürkischen Charakteristika der 
mordwinischen Hochzeitszeremonie sind möglicherweise von den Mischärtataren oder bereits von früheren Tataren oder den Bolgaren übernommen worden. Schließlich weist die ersanische und mokschanische Hochzeitszeremonie bemerkenswerte Gemeinsamkeiten auf, was entweder bedeutet, daß die Kontakte auf eine - urmordwinische - Periode der Zeit vor der mongolischen Eroberung datiert werden oder daß parallele Kontakte sowohl zu den Ersanen als auch zu den Mokschanen bestanden haben müssen.

Was die Klagehochzeit anbelangt, hat die Einflußnahme in entgegengesetzter Richtung stattgefunden: Die mischärtatarische Kultur hat sich durch Entlehnung bereichert. Die Abschiedsklage der Braut kann zwar ein Überrest aus einer eigenen Tradition sein, wie auch Muchamedova vermutet (1972, S. 227-), aber die Entwicklung der Brautklage zu einem Element, das die Hochzeitszeremonie wesentlich trägt, ist eine Entlehnung aus der Kultur der Nachbarvölker, der Mordwinen und der Russen. Muchamedova geht von russischem Einfluß in der Entstehung der mischärtatarischen Brautklage aus. Sie meint, sowohl die Serie der Brautklagen, die durch den "Abend des Mädchens" ausgelöst wird, als auch die, die mit der "Hahnen-Röte-Klage" beginnt, ließen sich dadurch erklären (Muchamedova a. a. O. S. 227-). Allem Anschein nach haben jedoch die mordwinischen Bräute bei der Eröffnungsklage der mischärtatarischen Hochzeit, der "Hahnen-Röte-Klage", Pate gestanden.

Die Gattung der Brautklage, die die tschuwaschische und die mischärtatarische Tradition von den Nachbarvölkern übernommen hat, soll im folgenden charakterisiert werden.

Osipov zufolge klagt die tschuwaschische Braut zweimal während ihrer Hochzeit so, daß die Klage zu einem Grundelement der Zeremonie wird; beide Male versammeln sich alle Anwesenden, um die Klage zu hören. Die erste Phase ist genau die eben erwähnte des Beginns der Brautklage (Osipov 1985, S. 49). Sobald ihr die Schwester und Schwägerin beigebracht haben zu klagen, stimmt die Braut, vom Geigenspieler ihrer Hochzeitsgesellschaft begleitet, die Klage an (Paasonen 1949, S. 26-). Sie klagt über "den bevorstehenden Abschied von dem Haus, in dem sie seit ihrer Geburt gelebt hat; über den Abschied 
von Anverwandten und Freundinnen; sie klagt ihre Eltern der Auslieferung an; und beschreibt schließlich ihre trostlose Zukunft als Ehefrau und Dienerin des unbekannten Mannes und seiner Familie" (Sirotkin 1965, S. 26-).

Die zweite grundlegende Klagephase der Hochzeit gehört laut Osipov dem Ende der Zeremonie an, wenn die Jungvermählte im Heim des Mannes vor seinen Eltern klagt; auch diese Klage wird von allen Anwesenden angehört (Osipov 1985, S. 49. Diese Klage oder ihr Vortrag wird jedoch in keiner anderen Beschreibung tschuwaschischer Hochzeitsbräuche, die ich konsultiert habe, erwähnt. Sie muß zu den Empfangszeremonien gehören, weil der Braut nach den Empfangsriten die Kopfbedeckung entfernt wird und somit die Vorraussetzungen für das Klagen nicht mehr gegeben sind.)

Alle anderen Brautklagen fügen sich laut Osipov verschiedenen Momenten der Hochzeitsablaufs ein: dem Treffen auf den Festzug des Bräutigams, dem Abschied vom Elternhaus und den Besuchen in den Häusern der Verwandten, insbesondere beim Eintreten und Verlassen des Gebäudes. Während die Braut die Klagelieder vorträgt, entsteht durch das gleichzeitige Vortragen von Hochzeitsliedern durch ihre Freundinnen und weiblichen Verwandten eine eigenartige Polyphonie (Osipov 1985, S. 49-).

Die Klagelieder der tschuwaschischen Braut sind voller dichterischer Bilder. Die folgenden Beispiele sind Übersetzungen von Klageliedern, die von Mészáros aufgenommen wurden. Dabei handelt es sich jeweils um die ersten Klagen der Braut. "Schwarze, schwarze Krähen / bedeckten das Dach des Hauses./ Das schwarze Volk von sieben Gästen / bedeckte das Haus meines Vaters." "Hie und da auf der Wiese mähte ich Heu, / dabei fand ich einen Apfelbaum. / Doch der Apfelbaum ist ohne Laub, / und ich bin jung und verzweifelt." "Im Quellgebiet des Bächleins / gibt es viele Himbeeren und wenig Erde./ Im Quellgebiet des großen Baches / gibt es wenig Himbeeren und viel Erde. / Im Haus meiner Eltern gibt es viel Güte und wenig Zeit./ Im Haus der sieben Fremden / gibt es wenig Güte und viel Zeit.” (Mészáros 1909, S. 437-). "Die Perlen-Zweig-Bäume stehen in Grüppchen./ Was ist überflüssig in der Gruppe? / Seit dem Morgengrauen dieses Tages / heute bin ich überflüssig." (Mészáros 1912, S. 203). 
Der Aufbau des Textes der tschuwaschischen Brautklage entspricht also dem des lyrischen Liedes: Der Anfang der Strophe mit vier Versen bringt eine naturlyrische Schilderung, das Ende eine analoge realistische Beschreibung (Vikár - Bereczki 1979, S. 82; s. Beispiele auch bei Paasonen 1949, S. 303- und Mészáros 1912, S. 48-). Außerdem berichtet Osipov, der Vers der Brautklage sei 7silbig, wie er es besonders im Gebiet der Anat-Jenči-Tschuwaschen auch bei anderen Liedtypen sei, vor allem bei den Hochzeitsliedern. Dieses Gebiet habe am besten fremden Einflüssen standhalten können (a.a. O. S. 50).

Die Klagemelodie der Anat-Jenči-Tschuwaschen besteht aus vier Phrasen; die Melodie der Anatritschuwaschen ist einfacher und besteht aus nur zwei Phrasen. Die Tonleitern beider Gebiete sind pentatonisch. In dem Gebiet der Anat-Jenči-Tschuwaschen gibt es keine halben Tonschritte; in dem von den Anatris bewohnten Gebiet sind sie an bestimmten Stellen möglich (Osipov a. a. O. S. 50-). Außerhalb der Republik der Tschuwaschen (Simbirsk, Samara, Saratov) besteht die Klage aus einer einphrasigen Melodie, obwohl der Text zwischen vier verschiedenen Versen unterscheidet. Die Melodie bewegt sich fast ausschließlich innerhalb einer Terze und beinhaltet Halbtonschritte. Osipov betont, daß die tschuwaschische Folklore dieses Gebietes meist durch die Nachbarvölker beeinflußt worden ist, d. h. durch die Russen, die Mischärtataren und die Mordwinen (a.a. O. S. 54-).

Wenn man die vielen Gemeinsamkeiten in der tschuwaschischen und mordwinischen Hochzeitszeremonie betrachtet, ist man geneigt, die einphrasige tschuwaschische Melodie, die sich nur innerhalb einer Terze bewegt, als Lehngut aus der mordwinischen Klageliedmelodie zu betrachten. Osipovs Auffassung, die tschuwaschische Brautklage beschränke sich auf das Anatri- und Anat-Jenči-Gebiet und schließe also nicht das Virjalgebiet mit ein, ist bereits weiter oben behandelt worden.

Die Klagen der mischärtatarischen Hochzeit konzentrieren sich ebenfalls auf zwei Phasen. Während der Nacht, die auf den "Abend des Mädchens" folgt, d.h. vor dem Morgengrauen, muß die Braut ihre Morgenröte-Klage, die "Hahnen-Röte-Klage", vortragen, und danach klagt sie Abschieds- und Vorwurfsklagen (Muchamedova 1972, S. 161-). Der andere Augenblick in der Mischärtatarenhochzeit, zu dem die Kla- 
gen gehören, ist der Moment des Aufbruches, wenn sich die Braut von ihrem elterlichen Haus verabschieden muß (a.a.O. S. 166).

Die erste Klage der mischärtatarischen Braut, die "Hahnen-RöteKlage", ruft einem natürlich die ersanische Braut ins Gedächtnis, die nach der Bestätigung der Verlobung in der Nacht nach dem ersten Hahnenschrei, aber noch vor der Morgenröte, draußen ihre erste große Klage ihren Ahnen vortragen muß; dieselbe Klage wird sie in der Nacht vor dem Tag ihrer Hochzeit wiederholen müssen. Die mischärtatarische Braut begnügt sich damit, lediglich das Fenster zu öffnen und gen Osten zu klagen: "Graut der Morgen schon? / Gibt es Sterne in der Morgenröte? / Ich klage vor dem Morgengrauen. / Hat keiner mit mir Mitleid?" (Muchamedova 1972, S. 161). Die Morgenröte bzw. das Morgengrauen spielt auch in der russischen Brautklage eine Rolle, aber die russische Braut klagt erst nach dem Morgengrauen, die mordwinische wiederum schon davor, d.h. solange es ihr noch möglich ist, mit den Vorfahren Kontakt aufzunehmen (Bartens 1990, S. 113-). Die Betonung des Jenseitigen, der Welt der Verstorbenen, die für die mordwinische Klage so typisch ist, fehlt bei der mischärtatarischen Klage völlig. Trotzdem ist die Verwandtschaft der mischärtatarischen und der mordwinischen Klage unübersehbar.

Nachdem die Braut die "Hahnen-Röte-Klage" vorgetragen hat, geht sie und weckt ihre Mutter mit der folgenden Klage: "Flocken, Schneeflocken / kleben am ganzen Holzstoß im Hof. / Steh' auf, Mutter,/ deine unglückliche Tochter klagt." Am Bett ihrer Freundinnen klagt sie: "Steht auf, Freundinnen, steht auf, / klagt an meiner Stelle die "Hahnen-Röte-Klage!" / Wir klagen seit dem Morgengrauen, wir wollen uns zu Glück verhelfen." Sobald die Braut alle geweckt hat, klagt sie: "Ich schickte einen Pfeil, als ich das Fenster öffnete, / ich habe seine Spitze verloren. / Ich klage mit trauriger Stimme, / ich habe alle geweckt." Während die Freundinnen das Frühstück verzehren, das ihnen die Mutter der Braut zubereitet hat, klagt diese: "Ich bin über die Türschwelle getreten und dabei in eine Pfütze gefallen ,/ ich habe meinen rechten Fuß naß gemacht. / Ich bin an meinen Freundinnen vorbeigegangen und habe mich auf die Vorderbank gesetzt. / Mein junges Herz zog sich zusammen." Die Freundinnen setzen sich neben die Braut, alle in denselben großen Umhang gehüllt, und klagen alle gleichzeitig. Die 
Braut klagt ihre Eltern an: "Ihr habt einen Topf für das Fettgebäck aufgehängt, / ihr dachtet, das Fett ginge nicht über. / Zu früh habt ihr mich weggegeben, / ihr dachtet, ich bliebe mein Leben lang sitzen." "Ich ging hin und warf Körner / vor die Gans, die brütete. / Wenn ich hier noch ein Jahr lang säße, / bliebe ich dennoch nicht für immer." Die an den Bruder und die Schwägerin gerichtete Anklage lautet folgendermaßen: "Die Blumen blühen hinter unserem Haus. / Der Bruder sagt: Es sind keine Blumen. / Die Schwägerin sagt: Das Jahr ist nicht so, / daß man noch ein Mädchen füttern könnte." Zu dieser Phase gehört auch die folgende Klage: "In meinem rauhen bestickten Hemd / sind die Achselflicken aus Kumatschstoff. / Ich hätte dies bestimmt nicht erlebt, / wäre ich als Kind gestorben." (Muchamedova 1972, S. 161-). ${ }^{2}$

Die zweite Phase der mischärtatarischen Hochzeit, während der Brautklagen angestimmt werden, ist der Augenblick des Aufbruchs aus dem Elternhaus. Wenn die Eltern der Braut sie segnen, umarmt sie sie und klagt: "Ich trat über die Schwelle, blickte auf die vorderste Bank. / Komm, Vater, segne mich, ich gehe für immer von euch fort" (Muchamedova a.a. O. S. 166).

Die Struktur der mischärtatarischen Klage entspricht der der tschuwaschischen und demnach auch der des türkischen lyrischen Liedes. Der Anfang der Strophe aus vier Versen ist metaphorisch, das Ende zeigt eine Parallele zu einer realen Situation. Sehr häufig scheint der Vers eines mischärtatarischen Liedes aus sieben Silben zu bestehen, aber zur Strophe gehört immer auch ein Bruch im Versfußschema, z. B. zugunsten eines achtsilbigen Verses (vgl. z. B. Paasonen 1953, S. 121-; Vikár - Bereczki 1979, S. 87; 1989, S. 49). Der Vers der von Muchamedova niedergeschriebenen Klagen ist etwas länger, oft 9-, 10oder 11silbig, aber auch ihre Notizen zum Hochzeitslied, zum Spottlied, weisen längere Verse auf (Muchamedova a.a. O. S.165).

Viele mischärtatarischen Bräute haben es Mitte des letzten Jahrhunderts aufgegeben, selbst zu klagen; für sie sind zwei Klagefrauen angestellt worden, damit diese statt ihrer klagten. Die Klagefrauen sitzen genauso wie früher die Bräute mit bedeckten Häuptern; sie sitzen am selben Ort "in der schönen Ecke", wo die Braut selbst ihre Klagen vorzutragen pflegte. Während die Klagefrauen die Klagelieder ertönen lassen, sitzt die Braut mit ihren Freundinnen hinter dem Bettvorhang 
und schluchzt laut (Muchamedova a. a. O. 167). Muchamedova hat keine Klageliedtradition im östlichen Siedlungsgebiet der Mischärtataren, im Gebiet Buinsk, vorgefunden.

Die tschuwaschischen ebenso wie die mischärtatarischen Brautklagen geben ihren fremden Ursprung nicht ohne weiteres preis - und fremdartig ist an ihnen ja auch nur die Tatsache, daß sie während mehrerer Phasen der Hochzeit vorgetragen wurden. Die Brautklage fand schon in der eigenen Volksdichtung einen geeigneten Nährboden: in der Totenklage und der möglicherweise daraus bereits entstandenen Abschiedsklage der Braut. Paasonen bezeichnet die tschuwaschische Totenklage als "Gebet": "ein altes Weib oder ein Greis weint das Gebet" (Paasonen 1949, S. 71); Magnickij verwendet den Terminus "Lied", pesnja (Magnickij 1881, S. 164); Mészáros' Terminus lautet "Klagelied”, sirató dal (Mészáros 1909, S. 221). Im Text der Totenklage kann man sowohl im Gebiet der Anatritschuwaschen, aus dem der Text von Paasonen kommt, als auch dem der Virjaltschuwaschen, aus dem die Texte von Magnickij und Mészáros stammen, die gleichen Formeln wiederfinden. Für die mischärtatarische Totenklage habe ich keine Beispiele gefunden.

Die tschuwaschischen Bräute haben die von den mordwinischen Bräuten entlehnte Brautklage dem Kode ihrer eigenen Dichtung angepaßt. Die mischärtatarischen Bräute sind ebenso vorgegangen, als sie sich die ursprünglich mordwinische oder russische Brautklage aneigneten. Das Verfahren ist das gleiche gewesen wie bei all denen, die Klagen vorgetragen haben. So können bei einer wogulischen Frau keinerlei strukturelle Unterschiede zwischen einer Totenklage und einem persönlichem Lied festgestellt werden. Die syrjänische Frau verwendet dieselben Elemente für die Toten- und Brautklage, für das Wiegenlied und für das persönliche Lied (Bartens 1986a, S. 41-). Das karelische Klagelied sowie der Joiku strukturieren den Text auf die gleiche Weise; die Klassifikation geschieht aufgrund der Melodie (Väisänen 1990, S. 30-, 50-, 139-). Im ingrischen Gebiet sowie in Estland, wo "das Vortragen vom Runenlied hauptsächlich ein Zeitvertreib der Frauen gewesen ist" (Väisänen, a.a. O. S. 90), kann das Klagelied eine kalevalische Form annehmen (vgl. Väisänen a. a. O. S. 49, 139). Die mordwinische Brautklage unterscheidet sich strukturell nicht von der übrigen Hochzeits- 
folklore (Bartens 1990, S. 108-). Die Tscheremissen und die südlichen Wotjaken tragen Totenklagen vor, die denselben Strophenaufbau haben wie ihre lyrischen Lieder (z. B. Bereczki 1971, S. 66. Weitere Beispiele bei Vikár - Bereczki 1971, Nummer 22, 23, 120; Vikár - Bereczki 1989, Nummer 70 und 152). Daß Čurakova bei den südlichen Wotjaken eine lange, nicht weiter in Strophen aufgeteilte Totenklage vorgefunden hat (Črakova 1980, S. 226-), zeugt nicht von der textuellen Eigenart der Totenklage, sondern davon, daß die südlichen Wotjakinnen früher auch andere, nicht in Strophen unterteilte Dichtung gekannt haben, und zwar höchstwahrscheinlich eine auf Parallelismus aufbauende Dichtung, wie sie heute noch bei den Syrjänen erhalten ist.

In zweierlei Hinsicht unterscheidet sich die Totenklage allerdings von allen anderen Klagen. Sie scheint konservativer als die anderen zu sein, und sie ist gewöhnlich weniger stabil als die Hochzeitsklage. Dies beruht jedoch nicht auf der Struktur des Textes, sondern ist durch die besondere Situation bedingt. In vielen Traditionen kann für die Braut eine Stellvertreterin angeworben werden, und wenn die Braut selbst die Klagelieder vorträgt, hat sie ihren Part zu Genüge üben können. Im Gegensatz dazu muß die Totenklage immer von der Mutter, Ehefrau oder Tochter selbst, in einer für diese neuen Situation, vorgetragen werden.

Die auf Parallelismus beruhende, nicht in Strophen unterteilte Dichtung stellt die älteste Dichtung der finnisch-ugrischen Völker dar (vgl. Väisänen 1990, S. 51, 130-). Es ist möglich, daß der Vers eine konventionelle Silbenstruktur gehabt hat. Dies hat Chelimskij für die samojedische Dichtung bewiesen (Chelimskij 1989, S. 1-, 38). Es wird wohl eine besondere Form des Verses für die sakrale Dichtung gegeben haben, die sich von der der profanen Dichtung unterschied (vgl. Chelimskij a.a. O. S. 8-, 29: Die sakrale Dichtung der Juraksamojeden besitzt einen 8silbigen Vers, während der 6silbige Vers bei der übrigen Dichtung überwiegt). Die sakrale Dichtung ist allerdings in verschiedenen Registern vorgetragen worden, je nach dem, wie stark das Recht des jeweiligen Publikums auf die heilige Tradition war, wie es für die wogulische Tradition nachgewiesen worden ist: Sie wurde als Dichtung vermittelt; als poetische Prosa; als einfache Prosa; als Märchen; derart verdunkelt, daß die charakteristischen Züge der eigenen Gesellschaft nicht mehr erkenntlich waren (Schmidt 1985, S. 565-). 
Der alte Kode der Dichtung hat sich am besten an der nördlichen Peripherie erhalten. Weiter südlich, wo die Frauen den Durchbruch bis in die Sphäre des heiligen Gedichtes geschafft haben und durch die $\mathrm{Be}$ rührung mit fremden poetischen Kulturen zu neuen dichtungstechnischen Mitteln gefunden haben, hat die Dichtung der Frauen neue Formen erhalten. Die Gestalt der Totenklage wandelt sich am langsamsten, wie Curakovas Fund bei den südlichen Wotjaken bewiesen hat.

Es ist nicht möglich, die konkreten Elemente, Formeln, der mordwinischen oder russischen Brautklage in der tschuwaschischen oder mischärtatarischen Klage wiederzuerkennen, was als Ausdruck der Stärke des eigenen Kodes betrachtet werden kann, dem die tschuwaschischen und mischärtatarischen Bräute ihre Brautklage angepaßt haben. (Hingegen ist es erstaunlich, daß die karatajmordwinischen Bräute beim Übergang zum tatarischen Kode altes Formelmaterial aus ihrer mordwinischen Brautklage beibehalten haben; auch dies ist ein Ausdruck der Vitalität des eigenen ursprünglichen Kodes. Siehe Paasonen 1903, S. 20-21.) In der Themenwahl gibt es freilich Berührungspunkte; man erinnere sich z.B. der "Hahnen-Röte-Klage".

Ein konkreter Beweis für die Beziehungen zwischen tschuwaschischer und mordwinischer Hochzeitsfolklore läßt sich jedoch finden, wenngleich aus den bereits genannten Gründen nicht im Bereich der Brautklage. Eine poetisch bemerkenswerte Gattung der tschuwaschischen Hochzeitsfolklore ist die Rede in Gedichtform, salamalik, die der Zeremonienmeister der Gesellschaft des Bräutigams nach ihrem Eintreffen im Haus der Braut hält. Nach Prokop'evs Bericht werden in der Rede die Hochzeitstagsgerichte folgendermaßen gelobt: "Für diesen Schmaus ist gekocht und gebraten worden: Der Herr des Hauses besaß einen siebenjährigen Stier. Während dieser sieben Jahre weilte er keine sieben Male unter der Herde - jetzt ist er zu Ehren des Bräutigams für die Festtagstafel geschlachtet worden. Für den zweiten Teller hatte der Hausherr einen fünfjährigen schwarzen Bock. Während dieser fünf Jahre weilte er keine fünf Male unter der Herde, er stieß mit Kopf und Hinterteil - jetzt wurde er zu Ehren der Hochzeit unseres Bräutigams geschlachtet. Für den dritten Teller hielt der Hausherr einen пырень (ein einheimischer Vogel) bereit. Während dieser drei Jahre flog er keine drei Male auf die Erde. Er flog nur vor sich hin und landete schließ- 
lich mit weit ausgebreiteten Flügeln auf dem Dachfirst - jetzt schlug der Sturm ihn durch Gottes Willen herunter. Der Hausherr tötete ihn und bereitete ihn für die Festtafel zu." (Prokop'ev 1903, S. 19). In der Hochzeitsbeschreibung von Mészáros gibt es eine entsprechende Stelle in der Rede des Zeremonienmeisters des Bräutigams, die von einem Stier, einem Bock und einem Puter handelt (Mészáros 1909, S. 447-, 453).

Der Zeremonienmeister des Bräutigams, der Evsev'ev zufolge erst in jüngster Vergangenheit durch eine weibliche Figur der russischen Tradition ersetzt worden ist, beschreibt bei einer mordwinischen Hochzeit ebenfalls die Gerichte, wenn die Verwandten der Braut zur Endphase der Hochzeit in das Haus des Bräutigams eingeladen werden: "Es gibt, womit man bewirten kann; es gibt, was man anbieten kann. (...) Einen siebenjährigen Stier schlachtete er; seine Hörner durchlöcherten die Traufe, sein Schwanz reichte bis nach Moskau, und man könnte eine ganze Stadt mit seiner Haut zudecken. Einen vierjährigen Bock schlachtete er; seine Eingeweide wurden einem Geiger überlassen, seine Hörner wurden mit Schnupftabak gefüllt. Einen dreijährigen Hahn schlachtete er; jener hatte drei Singfedern." (Evsev'ev 1966, S. 294. Ein Mitglied der Gesellschaft des Bräutigams trägt ein Schnupftabakhorn bei sich - a.a. O. S. 97).

Im Haus des Bräutigams hatten die Frauen das Hochzeitsgebäck gelobt: "Was verbirgt es in sich? Ein dreijähriger Stier ist darin; bis nach Kasan stochert sein Schwanz, in das Firmament stochern seine Hörner. Mit seinem Schwanz zieht er Wasser, mit seinen Hörnern trägt er Wasser. Was verbirgt sich noch in ihm? Ein zweijähriger Bock ist in ihm. Seine Hörner biegen sich zu Armreifen, zu Ringen biegt sich seine Wolle. Was ist noch in ihm? Ein einjähriger Hahn ist in ihm. Er hat drei Singfedern, er hat drei Wahrsagefedern, seine Füße sind in Kupfer gestampft, sein Schnabel in Silber getaucht" (UPTMN 6:1, S. 237-).

Die Mordwinen opferten einen Stier, ein Schaf oder eine Gans, wenn sie im Sommer oder im Herbst nach der Getreideernte eine Opferzeremonie für die Getreide- oder Feldmutter veranstalteten (Harva 1942, S. 134, 135). Mancherorts wurde auch dem Donnergott Purgińe ein Stier oder Schaf geopfert (Harva a. a. O. S. 134, 101). Sowohl der Stier, der dem Donnergott geopfert wurde, als auch der, der der Feldmutter geopfert wurde, mußte bunt sein (a.a. O. S. 134). Wenn bei den 
Opferfeierlichkeiten zu der Getreide- oder Feldmutter um Regen und Getreidewachstum gebetet wurde (ebd.), fragt man sich, ob es sich nicht im Grunde auch hier um den Kult des Donnergottes Puŕgine handelt. Auch zu ihm wurde für Regen gebetet, besonders in Zeiten der Dürre (a.a.O. S. 101).

Der Donnergott, der in den agrarischen Kulturen so wichtig ist, ist bei den Mordwinen sogar dem Namen nach baltischen Ursprungs. Der baltische Perkunas machte das Land fruchtbar. Perkunas konnte die Gestalt eines Stieres oder eines Bockes annehmen. Mit Hilfe dieser Tiere sorgte er auch für die Fruchtbarkeit der Menschen. Die Taube und der Vogel Kukis oder Kukutis, der einen Federschopf auf dem Kopf trug, waren seine Attribute und Begleiter; man glaubte, sie steigerten die männliche Potenz (Gimbutas 1983, S. 236). Die Letten opferten einem aus dem 17. Jahrhundert erhaltenen Bericht zufolge dem Gott Perkons einen Stier, einen Bock oder einen Hahn, wenn sie ihm während der Trockenzeit um Regen anflehten (Harvilahti 1990, S. 67).

Sowohl bei der tschuwaschischen als auch bei der mordwinischen Hochzeit ist es ein Vertreter der Familie des Bräutigams, der mit dem Stier-Bock-Hahn-Gericht prahlt, denn dies gehört zu den Attributen des Bräutigams. Das Attribut der mordwinischen Braut ist das Getreide: Die ganze Verwandtschaft füttert sie an ihrem letzten Tag zu Hause mit Brei. Das große Hochzeitsgebäck, das die Frauen der Verwandtschaft des Bräutigams gebacken haben, wird am Hochzeitstag auf den Tisch im Haus der Braut gebracht und soll sie symbolisch ersetzen. Ihre Verwandtschaft verspeist das Gebäck, nachdem die Braut ihr Zuhause verlassen hat (Evsev'ev 1966, S. 90). Mancherorts wurde es mit einem aus Teig geformten Pferd mit Reiter verziert (ebd.). Im Haus des Bräutigams wurde es bis zum Aufbruch von dessen Festzug an der Stelle verwahrt, wo dann das Hochzeitsbett stehen sollte, und die Frauen, die das Gebäck trugen, imitierten Pferde, insbesondere wieherten und stampften sie (a.a. O. S. 94). Auch der wotische Bräutigam hat der Familie der Braut ein großes gefülltes Gebäck gebracht, dessen Name bereits seine Funktion verriet: Es handelte sich um ein "Brunstgebäck". Das Imitieren von Pferden ist auch aus der wotischen Hochzeitstradition bekannt, es wird ebenfalls von Frauen ausgeführt (Ariste 1974, S. 78, 81). Slygina setzt das wotische "Brunstgebäck" mit dem Pferdekult in Verbin- 
dung (Slygina 1978, S. 267, 269, 271); indem sie sich auf Fedjanovič beruft, erwähnt Šlygina einen entsprechenden Brauch bei der mordwinischen Hochzeit (Slygina a. a. O. S. 271). Bei diesem mordwinischen Hochzeitsbrauch ist das Pferd zur Alternative oder gar zum Ersatz für Stier, Bock oder Hahn geworden. Um ein "Brunstgebäck" handelt es sich also, wenn die Frauen der Verwandtschaft des Bräutigams prahlen, sie hätten einen Stier, einen Bock und einen Hahn im Gebäck.

Das mordwinische Hochzeitsgebäck verbindet symbolisch die Elemente der "heiligen Hochzeit": Die Vereinigung der Getreidemutter und des Donnergottes hat stattgefunden. Die Braut, die mit ihrem Klagelied beginnt, sobald die Gesellschaft des Bräutigams angekommen ist und das Gebäck auf dem Tisch plaziert hat, bezeichnet das Gebäck denn auch als Getreidemutter (Evsev'ev 1966, S. 207). Auf ihrer "Flucht" in das Haus des Onkels klagt die Braut, sie flüchte vor der Gewitterwolke. In der Eheschließung der mordwinischen Braut und ihres Bräutigams wiederholte sich die "heilige Hochzeit".

In der tschuwaschischen Zeremonie gibt es die im mordwinischen Hochzeitsgebäck sichtbar werdende Vereinigung der beiden Elemente Mutter Erde/Getreidemutter und Stier/Donnergott nicht, was man als negativen Beweis dafür nehmen kann, daß die Stier-Bock-Hahn-Thematik bei den Mordwinen funktionell tiefer verankert und deshalb älter ist als bei den Tschuwaschen und daß sie folglich von diesen übernommen worden ist. Die weiter unten zu erörternde Auffassung von Egorov, die "heilige Hochzeit" habe auch zu den alten Grundelementen der tschuwaschischen Mythologie gehört, ist also mit meiner Argumentation unvereinbar. Es besteht kein Zweifel, daß der Mythos der "heiligen Hochzeit" in einer agrarischen Kultur entstanden ist.

Es handelt sich um eine der ältesten Mythen der Menschheit. Sie war bereits Bestandteil der altindogermanischen Kultur. In seiner Arbeit über die Salamaliktexte erinnert Egorov daran, daß in der Hymne VI:70 der Rigweda der Himmel als männliches Element in Stiergestalt dargestellt wirdund die Erde als weibliches Element, das der als Regen herabkommende Samen befruchtet (Egorov 1982, S. 114). Ihm zufolge gehört der Mythos über die Eheschließung zwischen Himmel und Erde auch zu den Grundelementen der tschuwaschischen Mythologie. Dieser Mythos habe eine Rolle bei der Entstehung der Hochzeitszeremonie gespielt 
(a.a. O. S. 115). Die Einheit des Stieres und des Wettergottes war schon für die antiken Hochkulturen des vorderen Orients charakteristisch. Es sind die als Inkarnation des Wettergottes Adad betrachteten Stiere, die das berühmte babylonische Ischtar-Tor schmücken. ${ }^{3}$

Die Ackerbaukultur, für die die "heilige Hochzeit", die Vereinigung von Donnergott und Mutter Erde, als Grundlage für den Erhalt des Lebens diente, florierte auch im ostseefinnisch-baltischen Raum (vgl. Salo 1990, S. 103-, 109-; Haavio 1958, S. 256-; 1961, S. 66-, 96-; Harvilahti 1990, S. 67-); die Mordwinen gehörten zum Einflußbereich derselben Kultur (z. B. Rüütel 1990, S. 91; Bartens 1991, S. 47). Über die Grenzen dieses alten Kulturkreises hinaus haben die Mordwinen ihren späteren Nachbarn die Information über das Opferfest des großen Fruchtbarkeitsgottes und der Mutter Erde, ihrer Hochzeit, vermittelt. Der Zeremonienmeister des tschuwaschischen Bräutigams hat die kollektive Erinnerung an jenes Fest in seiner großen Rede konserviert.

Dieser alte Kulturkreis war auch der Nährboden der Brautklage. In dieser Kultur, die sich auf die Viehwirtschaft und den Ackerbau stützte, traf der Mensch im Diesseits auf den Menschen im Jenseits. Die Verstorbenen führten ihr Leben als Sippen an ihrem neuen Aufenthaltsort fort (für die Balten s. Gimbutas 1983, S. 212, 214). Alle Entscheidungen der Familie, z. B. die Übergabe einer Braut an eine andere Familie, betrafen alle Mitglieder, auch die Vorfahren. Neben der Abschiedsklage, die sich von der Totenklage differenziert hat, entsteht parallel dazu die Klage, die aus der Braut ihr Subjekt macht. Die Braut nimmt mit ihrer Klage selbst Kontakt zu den Ahnen auf, und es gelingt ihr dadurch, sich von ihnen zu lösen (Konkka 1985, S. 182-; Rüütel 1990, S. 96; Bartens 1990, S. 120-).

Danach distanziert sich die Braut mit der gleichen Methode, mit dem Klagelied, von ihrem weltlichen Leben: von ihren Angehörigen, ihrer Verwandtschaft, ihrem Zuhause. In diesen Klagen wird somit die grundlegende Funktion der Klagelieder, die einmalige Möglichkeit des Überschreitens der Grenze zum Jenseits (Pino - Sarv 1981, S. 22), nicht wahrgenommen. Der Zusammenhang zwischen Klagelied und persönlichem Lied macht aber auch diesen Gebrauch verständlich. 


\section{Anmerkungen}

1 Vgl. die Karte im Mordwinischen Wörterbuch von Paasonen auf S. LIX.

2 Alle Beispiele für mischärtatarische Brautklagen, die ich gefunden habe, stammen aus Muchamedovas Abhandlung (161-, 199-).

3 Das vorderasiatische Museum. Berlin, 1990: 114.

\section{Bibliographie}

Achmet'janov 1981 = АХМЕТЬянОВ, Р. Г.: Общая лексика духовной культуры народов среднего Поволжья. Москва.

ARISTE, PAUL 1974: Vadjalane kätkist kalmuni. - Emakeele Seltsi Toimetised 10. Tallinn.

ARO, JUSSI 1967: Arabialainen kulttuuri. Helsinki.

Balašov - Marčenko - Kalmykova 1985 = БАЛАПІОВ, Д. М. - МАРчЕНКО, Е.

И. - КАЛмыковА, Н. И.: Русская свадьба. Свадебный обряд на Верхней и Средней Коксеньге и на Устюге (Тарногский район Вологодской области). Москва.

Balašov - Mart'janov 1985 = БАЛАшов, В. А. - МАРТЬЯНОВ, В. Н.: Мордва. - Народы Поволжья и Приуралья. Москва.

BALYS, J. Litauische Hochzeitsbräuche. - Contributions of Baltic University 9. Hamburg 1946.

BARTENS, RAJuA 1986a: Die Klagelieder der Komi. - Finnisch-Ugrische Mitteilungen 10. Hamburg

1986b: Siivekkäille jumalille, jalallisille jumalille. Mansien ja hantien runoutta. Helsinki.

1990: Die Todesmotive der mordwinischen Brautklage. - UralAltaische Jahrbücher. Neue Folge 9. Wiesbaden.

1991: Die permischen Klagelieder. - Ural-Altaische Jahrbücher. Neue Folge 10. Wiesbaden.

BENZING, JoHANNES 1959: Das Tschuwaschische. - Philologiae Turcicae Fundamenta I. Wiesbaden.

Bereczki s. Vikár, László - Bereczki, Gábor.

Bojarkin 1986 = БояРКиН, Н. И.: Инструменты и инструментальная музыка в мордовской свадьбе. - Музыка в свадебном обряде финно-угров и соседних народов. Таллинн.

Chabunova 1986 = ХАБУновА, Е. Е.: Протяжная песня в свадебном обрйаде калмыков. - Музыка в свадебном обряде финно-угров и соседних народов. Таллинн. 
Chelimskij 1989 = Хелимскии, Е. А.: Глубинно-фонологический изосиллабизм ненецкого стиха. - JSFOu 82. Helsinki.

ČISTOV, K.V. 1981: Pohjoisvenäläiset häät. - Pohjolan häät. Hg. MATTI SARMELA. Helsinki.

1982: Причитания у славянских и финно-угорских народов (некоторые итоги и проблемы). - Обряды и обрядовой фольклор. Москва.

Čižikova 1978 = ЧижиковА, Л.Н.: Свадебные обряды русского населения Украины. - Русский народный свадебный обряд. Ленинград.

Čurakova 1982 = ЧуРАКОВА, Р.: Традиционные обрядовые песни южных удмуртов. - Soome-ugrilaste rahvamuusika ja naaberkultuurid. Hg. I. RÜÜTEL. Tallinn.

Cuvaši = Чуваши. Этнографическое исследование. Чебоксары 1970.

Das vorderasiatische Museum. Staatliche Museen zu Berlin. 1990.

Der Große Brockhaus. Aktualisierte 18. Aufl., Bd. 8. Wiesbaden 1983.

Denisov - Ivanov 1985 = ДЕНиСов, П. В. - ИвАНОВ, Л. А.: Чуваши. Народы Поволжъя и Приуралья. Москва.

Divaev 1964 = ДивАЕв, А. А.: Несколько слов о свадебном ритуале киргизов Сыр-дарьинской области. - Казахская народная поэзия. АлмаАта.

Džumagulov 1960 = ДЖУМАГУЛОВ, А.: Семья и брак у киргизов чуйской долины. Фрунзе.

Egorov 1982 = ЕГОРОВ, Н. И.: Чувасский саламалик. - Чувасский фольклор. Специфика жанров. Чебоксары.

Evsev'ev 1966 = ЕвСевьЕВ, М. Е.: Избранные труды. Т. 5. Историкоэтнографические исследования. Саранск.

Fedjanovið 1978 = ФЕДянович, Т. П.: Черты сходства свадебной обрядности русских и мордвы. - Русский народный свадебный обряд. Исследования и материалы. Под ред. К. В. ЧистовА и Т. А. БЕРНШТТАМ. Ленинград.

VON GABAIN, ANNEMARIE 1963: Zentralasiatische türkische Literaturen I. Vorislamische alttürkische Literatur. - Handbuch der Orientalistik. V Altaistik. 1. Turkologie. Leiden - Köln.

Gemuev s. Tradicionnoe mirovozzrenie tjurkov južnoj Sibiri.

GIMBUTAS, MARIJA 1983: Die Balten. Volk im Ostseeraum. München - Berlin (Englische Originalausgabe 1963).

HAAVIO, MARTTI 1930: Savvaitovin, Lytkinin ja Wichmannin keräämät syrjääniläiset hääitkut. - Suomi V:10. Helsinki.

-1944-35: Über die finnisch-karelischen Klagelieder. - JSFOu. 47.3. Helsinki.

1958: Rauni. - Virittäjä. Helsinki.

1961: Kuolematonten lehdot. Helsinki. 
HARVA, UNO 1933: Altain suvun uskonto. Helsinki. 1942: Mordvalaisten muinaisusko. Helsinki.

[= HOLMBERG] 1964: Finno-Ugric Mythology. Siberian Mythology. The Mythology of All Races IV. New York.

HARVILAHTI, LAURI 1990: Jumalat, tammet, laulut. Piirteitä balttien kansankulttuurista. - Dainojen henki. Latvian ja Liettuan kirjallisuudesta ja kulttuurista. Hg. URPO VENTO. Helsinki 1990.

HÄMÄLÄINEN, ALBERT 1913: Mordvalaisten, tšeremissien ja votjakkien kosinta- ja häätavoista. Helsinki.

Holmberg 1964, s. HARVA, UNO.

JANHUNEN, JUHA 1988: Siperia. - Sana ja ruokokynä. Ulkoeurooppalaisen kirjallisuuden antologia. Helsinki.

Juadarov 1991 = ЮАДАРОВ, К. Г.: Сӱан обуча дӓ мыры. - Кырык мары сӱан. Йокар-Ола.

KANNISTO, ARTTURI 1958: Materialien zur Mythologie der Wogulen. Gesammelt von Artturi Kannisto. Bearbeitet und herausgegeben von E. A. VIRTANEN und MATTI LIIMOLA. MSFOu. 113. Helsinki.

KAPPELER, ANDREAS 1982: Russlands erste Nationalitäten. Das Zarenreich und die Völker der Mittleren Wolga vom 16. bis 19. Jahrhundert. Beiträge zur Geschichte Osteuropas 14. Köln - Wien 1982.

1992: Russland als Vielvölkerreich. Entstehung. Geschichte. Zerfall. München.

KÁROLY, LÁsZLó 1988: Siratóének. - Magyar néprajz V. Népköltészet. Budapest.

KONKKA, UNELMA 1985: Ikuinen ikävä. Karjalaiset riitti-itkut. Helsinki.

KORHONEN, MiKKO 1976: Suomen kantakielten kronologiaa. - Virittäjä. Helsinki.

KREINDLER, ISABELLE T. 1985: The Mordvinian Languages: A Survival Saga. - Sociolinguistic Perspectives on Soviet National Languages. Their Past, Present and Future. Ed. Isabelle T. Kreindler. Berlin - New York - Amsterdam.

LEHTINEN, ILDIKó 1979: Naisten korut Keski-Venäjällä ja Länsi-Siperiassa. Helsinki.

Lupinskaja - Safjanova $1978=$ ЛупинСКАЯ, В. А. - САФяновА, А. В.: Свадебные обряды населения Алтайского горного округа. - Русский народный свадебный обряд. Исследования и материалы. Под ред. К. В. ЧИсТОВА и Т. А. БЕРНшТАМ. Ленинград.

MÁCHAL, JAN 1918: Slavic Mythology. - The Mythology of All Races. Boston.

Magnickij 1877 = МАгницкии, В.: Песни крестьян села Беловолжскаго, Чебоксарскаго уезда, Казанской губернии. Казань. 1881: Материалы к обяснению старой чувасской веры. Казань. 
MAHLER, ELSA 1935: Die russische Totenklage. Ihre rituelle und dichterische Deutung (mit besonderer Berücksichtigung des großrussischen Nordens). Leipzig.

1960: Die russischen dörflichen Hochzeitsbräuche. Slavistische Veröffentlichungen 20. Berlin.

MAINOFF, W. 1883: Mordvankansan häätapoja. - Suomi II:16. Helsinki.

MENGES, KARL HEINRICH 1959: Die aralo-kaspische Gruppe. - Philologiae turcicae fundamenta I. Wiesbaden.

MÉSZÁROS, GYULA 1909: A csuvas ôsvallás emlékei. Budapest. 1912: Csuvas népköltési gyũjtemény. Budapest.

Mikušev - Cistalev 1968 = МикУІІЕВ, А.К. - ЧИСТАЛЕВ, П.И. Коми народные песни . Сыктывкар.

MNL = Magyar néprajzi lexikon. Budapest 1977-1982.

MNT III/A = A magyar népzene tára III/A. Lakodalom. Budapest 1955.

Muchamedova $1972=$ МухамедовА, Р.Г.: Татары-мишари. Москва.

MÜlLER, G. F. 1759: Sammlung Russischer Geschichte. III:4. St. Petersburg.

NeNOLA-KALlio, AILI 1981a: Itämerensuomalaiset itkuvirret. - Kansanmusiikki. Hg. ANNELI ASPLUND - MATTI HAKO. Helsinki.

1981b: Inkeriläiset itkuhäät. - Pohjolan häät. Hg. MATTI SARMELA. Helsinki.

1982: Studies in Ingrian laments. FFC 234. Helsinki.

Osipov 1985 = Осипов, А. А.: Свадебные напевы чужашей. - Чувасское народное творчество. Чебоксары.

PAASONEN, H(EIKKI) 1891: Proben der mordwinischen Volkslitteratur 1. JSFOu 9. Helsinki.

1897: Die türkischen Lehnwörter im Mordwinischen. - JSFOu 15:2. Helsinki.

1903: Die sogenannten Karataj-Mordwinen oder Karatajen. - JSFOu 21:1. Helsinki.

1939, 1947: Mordwinische Volksdichtung. Gesammelt von H. Paasonen. Herausgegeben und übersetzt von PAAVO RAVILA. II. MSFOu 81. Helsinki 1939. IV. MSFOu 91. Helsinki 1947.

1949: Gebräuche und Volksdichtung der Tschuwassen. Gesammelt von Heikki Paasonen. Herausgegeben von EINO KaRAHKA und MARTTI RÄSÄNEN. MSFOu 94. Helsinki.

1953: Mischärtatarische Volksdichtung. Gesammelt von Heikki Paasonen. Übersetzt und herausgegeben von EINO KARAHKA. MSFOu 105. Helsinki.

1990: H.Paasonens Mordwinisches Wörterbuch. Zusammengestellt von KAINO HEIKKILÄ. Band I. Unter Mitarbeit von HANS-HERMANN BARTENS, ALEKSANDR FEOKTISTOW und GRIGORI JERMUSCHKIN bearbeitet und herausgegeben von MARTTI KAHLA. LSFU XXIII, 1. Helsinki. 
Perevozčikova $1982=$ ПЕРЕВозчиковА, Т.: Своеобразие жанра причитаний в удмуртском фольклоре. - Финно-угорский музыкальный фольклор: Проблемы синкретизма. Тезисы докладов. Таллин.

1986: Свадебная песня как основа воссоздания поэтических форм эпоса пермских народов. - Проблемы эпической традиции удмуртского фольклора и литературы. Устинов.

PINO, VEeRA - SARV, VAIKE 1981: Setu surnuitkud I. Vihik 1. Tallinn.

Prokop'ev 1903 = ПРОКопьЕВ, К.: Брак у чувас. Казань.

Razumova - Koski 1980 = РАзумовА, А. П. - Коски, Т. А.: Русская свадьба Карельского Поморя. Петрозаводск.

RÓNA-TAS, ANDRÁS 1978: Bevezetés a csuvas nyelv ismeretébe. (Kézirat.) Budapest. 1982: The Periodization and Sources of Chuvash Linguistic History. Chuvash Studies. Ed. by ANDRÁs RÓNA-TAS. Asiatische Forschungen 79. Wiesbaden 1982.

RÜÜTEL, INGRID 1990: Die Schichten des Volkslieds der Setukesen und ihre ethnokulturellen Hintergründe. - FUF 49. Helsinki.

RÄSÄNEN, MARTTI 1945: Hochzeitsgebräuche der Mischär-Tataren. - Studia Orientalia 11:2. Helsinki.

SALO, UNTO 1990: Agricola's Ukko in the light of archaeology. A chronological and interpretative study of ancient Finnish religion. - Old Norse and Finnish Religions and Cultic Place-Names. Ed. TORE AHLBÄCK. Åbo. Samorodov 1980 = САмоРодов, К. Т.: Мордовская обрядовая поэзия. Саранск.

S. UPTMN 6:2

SARMEla, MATTI 1981: Suomalaiset häät. - Pohjolan häät. Hg. MATTI SARMELA. Helsinki.

SCHMIDT, ÉvA 1985: V. N. Csernyecov vogul folklór hagyatéka. - Ethnographia 96:4. Budapest.

Sirotkin 1965 = СиРОткин, М. Й.: Чувашский фольклор. Очерк устнопоэтического народного творчества. Чебоксары.

SPULER, BERTOLD 1983: Die Mordwinen - Vom Lebenslauf eines Wolgafinnischen Volkes. - Finnisch-Ugrische Mitteilungen 7. Hamburg.

Suraev - Korolev s. UPTMN 6:2

Szİ, ENIKô Finnugor hol-mi I. (Kézirat.) Budapest 1990.

Šachmatov $1910=$ IIIАХмАТов, А. А.: Мордовский этнографический сборник. С.-Петербург.

Šivljanova 1986 = ПивляновА, В. К.: Калмыцкая народная протяжная песня в свадебном обряде. - Музыка в свадебном обряде финноугров и соседних народов. Таллинн.

Šlygina 1978 = ШлыгинА, Н. В.: Водская свадьба (традиции и русское влияние). - Русский народный свадебный обряд. Исследования и материалы. Под ред. К. В. ЧистовА и Т. А. БЕРНпाТАМ. Ленинград. 
Tatary srednego Povolž'ja i Priural'ja = Татары среднего Поволжья и Приуралья. Москва 1967.

Tradicionnoe mirovozzrenie tjurkov južnoj Sibiri $=$ Традиционне мировоззрение тюрков южной Сибири. Отв. ред. И. Н. ГЕмУЕВ. Новосибирск 1989.

UPTMN = Устно-поэтическое творчество мордовского народа. 6:1 Ерзянская свадебная поэзия. Саранск 1972. 6:2 Мокшанская свадебная поэзия. Саранск 1975.

Varfolomeeva 1986 = ВАРФОЛОМЕЕВА, Т. Б.: Белорусский свадебный причет: национальная традиция и финно-угорские типологические параллели. - Музыка в свадебном обряде финно-угров и соседних народов. Таллинн.

Vdovin, s. UPTMN 6:1.

VIKÁR, LÁSZLÓ - BERECZKI, GÁBOR 1971: Cheremis folksongs. Budapest. 1979: Chuvash folksongs. Budapest. 1989: Votyak folksongs. Budapest.

Vladykin - Curakova 1986 = ВлАДЫКин, В. Е. - ЧурАКовА, Р. А.: Обряд “йыр-пыд сётон” в поминальном ритуале удмуртов. - Музыка в свадебном обряде финно-угров и соседних народов. Таллинн.

VOIGT, VILMOS 1983: Az érzelmek és a fájdalom eltávolitása (menyasszonysiratók). - Folklór és Etnográfia 9. Lakodalom. Hg. LÁsZLó NOVÁK ZOLTÁN UJVÁRY. Debrecen.

1987: Hungarian bride's laments. An enigmatic genre from a comparative point of view. - SIEF's third congress. The life cycle. April 8 12, 1987. Zürich.

VÄISÄNEN, A. O. 1990: Hiljainen haltioituminen. A. O.Väisäsen tutkielmia kansanmusiikista. Hg. ERKKI PEKKILÄ. Helsinki.

WICHMANN, YRJÖ 1893: Wotjakische Sprachproben I. - JSFOu 11:1. Helsinki. 1931: Volksdichtung und Volksbräuche der Tscheremissen. - MSFOu 59. Helsinki.

ZIMONYI, I. 1990: The Origins of the Volga Bulghars. - Studia Uralo-altaica 32. Szeged.

Žerebcov 1985 = ЖЕРЕБЦОВ, Л. П.: Коми (зыряне). - Народы ПоволЖья и Приуралья. Москва. 